\title{
Interactions between inorganic surface treatment agents and matrix of
}

\section{Portland cement-based materials}

\author{
Xiaoying $\mathrm{Pan}^{1}$, Zhenguo Shi ${ }^{2}$, Caijun Shi ${ }^{1}$, Xiang $\mathrm{Hu}^{1}$, Linmei $\mathrm{Wu}^{1}$ \\ 1. College of Civil Engineering, Hunan University, Changsha 410082, China \\ 2. Interdisciplinary Nanoscience Center (iNANO) and Department of Chemistry, Aarhus University, 8000, \\ Aarhus C, Denmark
}

\begin{abstract}
Magnesium fluorosilicate, waterglass, sodium fluorosilicate, and combination of waterglass and sodium fluorosilicate were used as surface treatment agents and their interactions with the Portland cement hydrates were studied. Thermogravimetric analysis (TGA) and fourier transform infrared spectroscopy (FT-IR) were employed to analyze the phase changes in the hardened cement pastes after surface treatments. A scanning electron microscope (SEM) with energy dispersive X-ray spectroscopy (EDX) analysis was adopted to examine the changes in morphologies and chemical compositions. The TGA and FT-IR results showed that the inorganic surface treatments could reduce the content of $\mathrm{Ca}(\mathrm{OH})_{2}$ in the surface layer of hardened cement, whereas the amount of calcium silicate hydrate (C-S-H) and silica gel increased. Combined treatment with waterglass and sodium fluorosilicate could generate more gel products, and made the sample surface denser than other treatments used in this work, because sodium fluorosilicate could accelerate the hardening of waterglass, and both waterglass and sodium fluorosilicate could reacte with cement hydrates respectively.
\end{abstract}

Keywords: surface treatment; cement; magnesium fluorosilicate; waterglass; sodium fluorosilicate

\footnotetext{
${ }^{1}$ Corresponding author: cshi@hnu.edu.cn, Tel: +86-0731-88823937, Fax: +86-0731-88823937
} 


\section{Introduction}

Durability of Portland cement-based materials is a major concern for reinforced concrete structures, which is governed by the ingress of aggressive substances, such as chloride, sulfate and carbon dioxide. Among many protective methods aiming at enhancing the durability of concrete, surface treatment has been concerned as an effective and economic method.

Surface layer of concrete usually refers to a $30 \mathrm{~mm}$ thick layer below the surface, generally thinner than protective layer [1]. Many properties of concrete are affected by the quality of surface layer which can improve by surface treatments [2]. The protective surface treatments are generally classified into three categories as literatures [3-5]: (a) surface coatings which form a continuous polymer film to create a physical barrier, (b) hydrophobic impregnation which can produce water-repellent capillary surface while leave the pores open $[6,7]$, and (c) pore blocking surface treatment agents which have partial or total pore-filling effect and thus reduce the surface porosity.

Most surface coatings and hydrophobic impregnation are organic polymers. Although organic polymers can significantly improve the durability of concrete, they have some drawbacks, such as poor fire resistance, possibly leading to crack and detachment, and hard to remove after losing effectiveness [6, 8]. Many coatings would greatly reduce the air permeability of concrete which could result in detachment of coatings from the matrix [9]. For hydrophobic impregnation, silane and siloxane are widely used around the world [6, 7]. Although silane and siloxane can prevent the ingress of water into concrete, their effects on the air permeability and carbonation are negligible. In addition, Medeiros et al. [10] reported that their capacity of inhibiting water penetration reduced significantly when the water pressure was higher than $120 \mathrm{kgf} / \mathrm{m}^{2}$. The author [11] also found that silane and siloxane did not have significant impact on the resistance to chloride diffusion. Furthermore, the aging resistance of organic polymers is poor, and they should not be used in long-life structures. Dhir [11] showed that silane and siloxane would decompose and lose their protective effects when the temperature was higher than $45{ }^{\circ} \mathrm{C}$. Levi et al. [13] found that the effects of silane and fluorinated polymers would reduce to $10 \%$ and $50 \%$ respectively after exposure to ultraviolet (UV) light. 
Since inorganic surface treatment agents have better ageing resistance, they draw more attention recent years. Silicate-based solutions, e.g. waterglass, potassium silicates and fluorosilicates are most common inorganic surface treatment agents [14]. Some studies demonstrated that waterglass treatment could reduce the water absorption and chloride diffusion, especially after post-treatment of cationic surfactant (alkyl quaternary ammonium salts) [14, 15]. Franzoni et al. [16] found that abrasion resistance of concrete was increased by waterglass treatment. However, there are some different results. Dai et al. [4] showed that waterglass hardly penetrated into concrete substrate. Ibrahim et al. [17] reported that waterglass treatment could not significantly improve the resistance to ingress of water and chloride ions. In addition, reaction of waterglass and $\mathrm{Ca}(\mathrm{OH})_{2}$ would generate $\mathrm{NaOH}$, which would increase the likelihood of alkali aggregate reaction $[8,18]$.

Recently, researches showed that magnesium fluorosilicate, waterglass, and sodium fluorosilicate had the capacity to enhance the resistance of concrete to water permeability, air permeability and carbonation [19, 20]. However, limited works focused on mechanisms of these inorganic surface treatments. In this paper, the mechanisms of these inorganic surface treatment agents, particularly the interactions of the surface treatment agents with cement hydrates, are investigated using thermogravimetric analysis (TGA), fourier transform infrared spectroscopy (FT-IR) examination, and scanning electron microscope (SEM) with energy dispersive X-ray spectroscopy (EDX) analysis.

\section{Materials and methods}

\subsection{Materials}

A P.I. 42.5 Portland cement with a specific surface area of $336 \mathrm{~m}^{2} / \mathrm{kg}$ was used. Its chemical compositions are shown in Table 1 . Natural river sand with a density of $2610 \mathrm{~kg} / \mathrm{m}^{3}$ was used as fine aggregate. The grading of the sand is shown in Table.2.

The following inorganic protective treatments were used: magnesium fluorosilicate solution with a concentration of 30 wt. \%, two waterglasses $\left(\mathrm{Na}_{2} \mathrm{O} \cdot \mathrm{nSiO}_{2}\right)$ with modulus (n) of 2 and 3, and sodium fluorosilicate. The watergalss with $\mathrm{n}=2$ was obtained by adding $5.92 \mathrm{~g}$ $\mathrm{NaOH}$ in $100 \mathrm{~g}$ industrial grade waterglass with modulus of 3 . The chemical compositions and physical properties of these waterglass solutions are shown in Table 3. Both the waterglass 
were mixed with water in the proportion of $1: 4$ by weight to make surface treatment agent solutions. Sodium fluorosilicate with a concentration of 2 wt. \% was considered, because it performed best in improving the efficiency of waterglass treatment [19-22].

\subsection{Mixture proportions and sample preparation}

Mortar cylinders with $50 \mathrm{~mm}$ diameter and $100 \mathrm{~mm}$ length were prepared for morphology and microstructure characterizations with water to cement ratio (w/c) of 0.45 and sand to cement ratio (s/c) of 1.3. Paste cylinder (110 mm diameter and $100 \mathrm{~mm}$ length) with same w/c was prepared for TGA and FT-IR analyses. All the samples were compacted on a controlled vibration table, and then covered with plastic films. The samples were kept in a laboratory at $20 \pm 1^{\circ} \mathrm{C}$ for 24 hours, and then cured in a standard moist room at $20 \pm 1{ }^{\circ} \mathrm{C}$ and $\mathrm{RH} \geq 98 \%$ until treatment.

\subsection{Surface treatments}

After curing for 6 days, both ends of each cylinder were cut off perpendicularly to its axis. The remaining parts with $50 \mathrm{~mm}$ thickness were dried in an room at $20 \pm 2{ }^{\circ} \mathrm{C}$ and $\mathrm{RH}=$ $55 \pm 5 \%$ for $24 \mathrm{~h}$ before surface treatment. The cutting surface near to the cast surface was considered as treated surface. In samples MF, W2, W3 and SF, the treated surfaces were brushed with surface treatment agents using a nylon brush every two hours for four times according to Table 4. In term of sample SF-W2, the same face was firstly brushed with sodium fluorosilicate every two hours for four times. And after 24 hours, waterglass treatment agent with modulus of 2 was applied on the treated surface for other 4 times. Then, all treated cylinders were placed back into the standard moist room at $20 \pm 1{ }^{\circ} \mathrm{C}$ and $\mathrm{RH} \geq 98 \%$ until testing.

\subsection{Methods}

\subsubsection{Thermogravimetric analysis}

Thermogravimetric analysis (TGA) analysis was performed on the paste samples after 7, 14 and 28 days of surface treatment. According to previous research, the penetration depth of the inorganic surface treatment agents in mortar was about $5 \mathrm{~mm}$ [20]. Thus, $1 \mathrm{~mm}$ thick surface layer below the treated face of each cylinder was ground into powder by a computer 
numerical control (CNC) machine. The collected powders were dried in an oven at $60{ }^{\circ} \mathrm{C}$ for 24h, and then they were sieved through a $125 \mu \mathrm{m}$ sieve and the fine powders were analyzed. The powders (about $10 \mathrm{mg}$ per each sample) were heated at $10{ }^{\circ} \mathrm{C} / \mathrm{min}$ from 20 to $1200{ }^{\circ} \mathrm{C}$ in a nitrogen atmosphere in a TGA instrument (Netzsch STA 409PC). The amounts of $\mathrm{Ca}(\mathrm{OH})_{2}$ and $\mathrm{CaCO}_{3}$ were quantified using the software of the TGA instrument according to the temperature ranges for dehydration of $\mathrm{Ca}(\mathrm{OH})_{2}\left(450 \sim 550{ }^{\circ} \mathrm{C}\right)$ and decomposition of $\mathrm{CaCO}_{3}\left(550 \sim 1000{ }^{\circ} \mathrm{C}\right)$ respectively.

\subsubsection{Fourier transform infrared spectroscopy}

The samples for fourier transform infrared spectroscopy (FT-IR) were the same as those prepared for TGA. The FT-IR spectra were obtained by Thermo Scientific IS10 FT-IR workstation and conventional $\mathrm{KBr}$ disc method. Approximately $1 \mathrm{mg}$ of powder was ground together with $100 \mathrm{mg}$ of IR-grade $\mathrm{KBr}$ for $5 \mathrm{~min}$ and pressed into a thin disc. Each sample was tested at a resolution of $2 \mathrm{~cm}^{-1}$ with 32 scans. The blank $\mathrm{KBr}$ pellet was tested at the same time as reference. The relative absorbance spectra over the range of $1400-400 \mathrm{~cm}^{-1}$ were subjected to a deconvolution analysis using the Peakfit 4.12 software with Gaussian peak shape and variable peak widths. The fitting process was performed according to the detailed procedure described in literatures [23, 24]. The reliability of the deconvolution was controlled by minimizing the typical component band number, and at the same time maintaining the regression coefficient $\left(\mathrm{r}^{2}\right)$ above 0.95

\subsubsection{ESEM/EDX}

A scanning electron microscope (SEM, Quanta FEG-200) equipped with energy dispersive X-ray spectroscopy (EDX) was used to analyze the morphology and changes in chemical compositions after treatment. The samples were dried at $60{ }^{\circ} \mathrm{C}$ for $24 \mathrm{~h}$ and coated with Au-Pd before experiment.

\section{Results}

\subsection{Effect of inorganic surface treatment on $\mathrm{Ca}(\mathrm{OH})_{2}$ and $\mathrm{CaCO}_{3}$ content}

The TGA quantified amounts of $\mathrm{Ca}(\mathrm{OH})_{2}$ and $\mathrm{CaCO}_{3}$ in the surface layers of samples after different surface treatments are shown in Fig. 1. The results in Fig. 1(a) shows that all the studied surface treatment agents can reduce the amount of $\mathrm{Ca}(\mathrm{OH})_{2}$ as compared to the 
reference sample (UNTR). Pastes treated with waterglass and sodium fluorosilicate have comparable but lower amount of $\mathrm{Ca}(\mathrm{OH})_{2}$ than that of MF sample. Dramatic reduction in $\mathrm{Ca}(\mathrm{OH})_{2}$ were observed in SF-W2 sample indicating that combination of sodium fluorosilicate and waterglass has a synergetic effect with respect to reduction of $\mathrm{Ca}(\mathrm{OH})_{2}$ content. It could be seen from Fig. 1(b) that the magnesium fluorosilicate and combined treatment slightly increased $\mathrm{CaCO}_{3}$ content, while the $\mathrm{CaCO}_{3}$ content was significantly increased in the pastes treated with waterglass and sodium fluorosilicate. The $\mathrm{CaCO}_{3}$ content of sample W2 were increased by $97 \%, 70 \%$ and 38\% compared with that of the control sample at 7, 14 and 28 days. This result indicated that these inorganic surface treatment agents could react with $\mathrm{Ca}(\mathrm{OH})_{2}$ and made carbonation in surface layer more easily during storage, as a result of the reaction with $\mathrm{CO}_{2}$ from the ambient environment.

The relationship between the increased formation of $\mathrm{CaCO}_{3}$ and consumption of $\mathrm{Ca}(\mathrm{OH})_{2}$ as compared to the amounts in UNTR samples at 28 day is plotted in Fig. 2. Since 1 mol $\mathrm{Ca}(\mathrm{OH})_{2}$ can generate $1 \mathrm{~mol} \mathrm{CaCO}_{3}$, Fig. 2 could provide evidence that the consumption of $\mathrm{Ca}(\mathrm{OH})_{2}$ in the sample MF and SF-W2 mainly attributed to the reaction between surface treatment agents and hydrated cement paste. In addition, the consumption of $\mathrm{Ca}(\mathrm{OH})_{2}$ did not accelerate carbonation of the surface paste in MF and SF-W2 indicated the surface treatments provided efficiency protective layer for the hydrated cement paste. Moreover, sodium fluorosilicate and waterglass with modulus of 2 consumed $0.064 \mathrm{~mol}$ and $0.077 \mathrm{~mol} \mathrm{Ca}(\mathrm{OH})_{2}$ respectively, while combined treatment only consumed 0.12 mol which was less than total consumption of $\mathrm{Ca}(\mathrm{OH})_{2}$ by $\mathrm{SF}$ and $\mathrm{W} 2$ alone. This indicated the sodium fluorosilicate reacted with watergalss. However, sample W2 and W3 formed more $\mathrm{CaCO}_{3}$ which were almost same mol of the consumption of $\mathrm{Ca}(\mathrm{OH})_{2}$. Though the mechanism needs more investigation, Watergalss treatment could accelerate the carbonation of $\mathrm{Ca}(\mathrm{OH})_{2}$ most pronounced, which would reduce the porosity based on previous researches [25, 26].

\subsection{Effect of inorganic surface treatment agents on $\mathrm{C}-\mathrm{S}-\mathrm{H}$}

Fig. 3 presents the FT-IR spectra over the range $2000-400 \mathrm{~cm}^{-1}$ for surface layers of the paste samples after different treatments. For the UNTR sample, the two main bands at 1430 $\mathrm{cm}^{-1}$ and $970 \mathrm{~cm}^{-1}$ are typical bands assigned to asymmetric stretching vibrations $\left(v_{3}\right)$ of $\mathrm{CO}_{3}{ }^{2-}$ 
and $\mathrm{Q}^{2}$ (Si-O) stretching vibrations respectively [23, 27-29]. Weak shoulders at $875 \mathrm{~cm}^{-1}$ and $1640 \mathrm{~cm}^{-1}$ are caused by the out-of-plane bending vibrations $\left(v_{2}\right)$ of $\mathrm{CO}_{3}{ }^{2-}$ and bending vibrations of $(\mathrm{O}-\mathrm{H})$ [29]. The small band at around $450-490 \mathrm{~cm}^{-1}$ is assigned to bending vibrations of Si-O-Si, indicating inactive silica glass [23]. The comparison of FTIR spectra shows significant changes in intensity at around $1430 \mathrm{~cm}^{-1}$ and $875 \mathrm{~cm}^{-1}$ which suggested the content of $\mathrm{CaCO}_{3}$. In line with the TGA data presented in Fig. 1, the FT-IR spectra also shows that the $\mathrm{CaCO}_{3}$ content in the surface layer is significantly increased by waterglass and sodium fluorosilicate treatments, while the intensity do not show obvious increase for samples MF and SF-W2.

Fig. 4 illustrates the result of deconvolution of the main band over the range 1200-800 $\mathrm{cm}^{-1}$ which can illustrate information about four tetrahedron elements of silica in C-S-H gel $[30,31]$. The reliability of the deconvolution procedure is controlled by to minimizing the number of vibration bands, with consideration of typical position for C-S-H gel. The band at around $840 \mathrm{~cm}^{-1}$ is due to $\mathrm{Si}-\mathrm{O}$ stretching vibrations at $\mathrm{Q}_{1}$ sites which is main element in unhydrated cement clinker, and the main band at around $973 \mathrm{~cm}^{-1}$ is assigned to $\mathrm{Si}-\mathrm{O}$ stretching vibrations at $\mathrm{Q}_{2}$ sites [29, 32]. The $\mathrm{Q}_{2}$ tetrahedron which indicates a wide range of $\mathrm{C}-\mathrm{S}-\mathrm{H}(\mathrm{Ca} / \mathrm{Si} \approx 2: 1)$ is the most common tetrahedron in well hydrated cement paste [29, 32]. The two bands at $1089 \mathrm{~cm}^{-1}$ and $1135 \mathrm{~cm}^{-1}$ are due to typical bands of $\mathrm{Q}_{3}$ and $\mathrm{Q}_{4}$ sites which are assigned to C-S-H with higher $\mathrm{SiO}_{2}$ content. The $\mathrm{Q}_{3}$ sites usually show in carbonated $\mathrm{C}-\mathrm{S}-\mathrm{H}$, and content of $\mathrm{Q}_{4}$ sites are relatively low in hydrated cement paste [33, 34]. In addition, the small band at $1036 \mathrm{~cm}^{-1}$ is consequently attributed to the binding of sodium onto a silicate-based gel [33].

Fig. 5 shows the standardized area percentages of the deconvolution FT-IR spectra of cement pastes on external surfaces after 7, 14 and 28 days of treatments. It could be seen that the area of band assigned to $\mathrm{Q}_{2}$ increased after surface treatments, especially waterglass and combined surface treatment. Compared with untreated paste, the area of band assigned to $\mathrm{Q}_{2}$ wad increased by 40\%, 31\% and 52\% for samples W2, W3 and SF-W2 at 7 days, and these band area was increased by 23\%, 28\% and 37\% at 28 days respectively. These indicated the effect of combined treatment lasted longer than waterglass treatment alone. It could also find that the effects of W2 waterglass occurred mainly within the first 7days, while the effects of 
W3 waterglass were more significant at later ages. In addition, the content of $\mathrm{Q}_{3}$ sites in the gel rose after waterglass, sodium fluorosilicate and combined treatments. Compared with UNTR sample, the area of the band assigned to $Q_{3}$ was increased by $39 \%, 49 \%, 25 \%$ and $29 \%$ in samples W2, W3, SF and SF-W2 at 28 days. The increase of $\mathrm{Q}_{3}$ sites is probably due to the carbonation of C-S-H, which was attributed by watergalss and sodium fluorosilicate treatments, and the reactions between surface treatments and cement paste. The content of $\mathrm{Q}_{4}$ sites was greatly increased by the magnesium fluorosilicate and combined treatment, as shown in Fig. 5(c). This indicated that these surface treatment agents could react with cement paste and formed silica gel. Moreover, the content of $\mathrm{Q}_{4}$ sites in samples MF and SF-W2 decreased with time, while the contrary trend was found in other specimens. This suggested that the silica gel formed in samples MF and SF-W2 was reactivity and could reacted with $\mathrm{Ca}(\mathrm{OH})_{2}$ to form C-S-H gel [26]. In term of silicate-based gel binding of sodium, its content greatly increased in samples W2, W3 and SF-W2. In Fig. 5(e), the total amount of gel products increased by following order at 28 day: SF $<\mathrm{MF}<\mathrm{W} 2<\mathrm{W} 3<\mathrm{SF}-\mathrm{W} 2$.

\subsection{Effect of inorganic surface treatment on morphology}

Highly crystallized portlandite and amorphous C-S-H are the main phases in all hydrated Portland cement [35]. The SEM images at a magnification of 2000 and 5000 of external surface of the mortar sample without treatment are shown in Fig. 6 (a) and (b). The EDX results are presented in Table 5. There were some small particles which were $\mathrm{CaCO}_{3}$ according to the EDX results in Points 1-3. These particles of $\mathrm{CaCO}_{3}$ are mainly from carbonation of portlnadaite which is thermodynamically less stable than the C-S-H phase [37]. Combining with the result of EDX analyses (Points 4-11), it could be found that the amorphous product was a mix of C-S-H gel and calcium carbonate. Since the tested points were located on the external surface which contacted with air directly, the surface paste would react with $\mathrm{CO}_{2}$ in air during curing. Though the content of $\mathrm{C}$ was relatively higher in the amorphous phase, it was difficult to distinguish the calcium carbonate from the C-S-H [35]. The $\mathrm{Ca} / \mathrm{Si}$ of the amorphous phase in this sample varied from 1.1 to 3.0 with a mean of 1.80 , which were similar with previous reports [36, 37]. The content of magnesium, sodium and potassium in the phase were relatively low. In addition, many micro pores which would 
attribute to the water permeability were observed in Fig. 6 [39].

Morphology of external surface on the mortar sample after magnesium fluorosilicate treatment can be observed in Fig. 7. Magnesium fluorosilicate led to a great change in morphology and microstructure of surface of cement-based matrix. The specimen surface was covered by many 1-10 $\mu \mathrm{m}$ cubes and micro-powder. According to EDX analyses (Points 1-3) shown in Table 6, the main elements in the micro-cubes were $\mathrm{K}, \mathrm{Mg}$ and $\mathrm{F}$, and their molar ratio was about 1: 1: 3 . The chemical composition of these micro-cubes was probably $\mathrm{KMgF}_{3}$. The complex fluoride $\mathrm{KMgF}_{3}$ is 1 to $17 \mu$ m cubic crystal which can be generated by reaction between $\mathrm{KF}$ and $\mathrm{MgF}_{2}$ [39-41]. This indicated that the magnesium fluorosilicate could react with $\mathrm{K}^{+}$in pore solution. Furthermore, EDX analyses showed this micro-powder probably was a mixture of silica gel and $\mathrm{KMgF}_{3}$. In the area uncovered by many cubic crystals, it could be seen that the surface of substrate was very smooth and dense. In addition, its chemical composition was quite different from the untreated sample. According to EDX results of Points 8-11, the calcium content in surface of substrate decreased significantly, while silica content increased.

Fig. 8 shows that the external surface of mortar sample treated with waterglass with modulus of 2. The SEM images revealed that two distinctive phases existed on the external surface. There were some robs-like crystals which growth in the pores of matrix. The diameter of these crystals ranged from 0.6-4 $\mu \mathrm{m}$. Most of them had hexagonal cross section, and some were hollow. According to the EDX result (Table 7, Points 1-3), the Ca, C and O were the main elements, and the composition of these product was probably $\mathrm{CaCO}_{3}$. The content of $\mathrm{CaCO}_{3}$ after $\mathrm{W} 2$ treatment was larger than that in the untreated sample, which was consistent with the results of TGA and FT-IR. The amorphous product formed in the waterglass-treated surface seemed to be less porous and more compact compared with that in the UNTR sample. It could also found that the average $\mathrm{Ca} / \mathrm{Si}$ ratio of the phase was around 1.25 , significantly lower than that in the control sample. The highest $\mathrm{Ca} / \mathrm{Si}$ ratio of the phase within the region was 2.17, and the lowest ratio was 0.34 . Thus, the $\mathrm{C}-\mathrm{S}-\mathrm{H}$ with low $\mathrm{Ca} / \mathrm{Si}$ ratio has high intrinsic strength and low permeability [40]. In addition, the content of $\mathrm{C}$ and $\mathrm{Na}$ in the phase increased after waterglass treatment. There are two possible reasons for the decrease of $\mathrm{Ca} / \mathrm{Si}$ ratio in the amorphous product: (1) watergalss could accelerate of carbonation of surface layer, 
which can change the $\mathrm{Ca} / \mathrm{Si}$, morphology and nanometer-level structure of C-S-H [41, 42], and (2) C-S-H gel generated from reaction between waterglass and $\mathrm{Ca}(\mathrm{OH})_{2}$ had lower $\mathrm{Ca} / \mathrm{Si}$ ratio than that from the hydration of cement paste. Since the $\mathrm{Ca} / \mathrm{Si}$ ratio influences mechanical, chemical properties and morphology of C-S-H, hydrated cement paste with lower $\mathrm{Ca} / \mathrm{Si}$ ratio after W2 treatment has less large pores than that with high Ca/Si ratio [43-45].

The SEM images of external surface of the W3 mortar sample can be observed in Fig. 9. The specimen surface was covered by two distinctive phases. According to EDX analyses, the block product (Points 1-3) and needle-like product (Points 4-6) were both $\mathrm{CaCO}_{3}$. It could be found that the shape of calcium carbonate were different from that shown in Fig. 8. According to previous studies, the change in morphology of the $\mathrm{CaCO}_{3}$ may be attributed to the variation of the $\mathrm{Ca} / \mathrm{Si}$ ratio in substrate. With the increase of $\mathrm{Ca} / \mathrm{Si}$ ratio, the content of calcite gradual increases while the aragonite calcium content decreases [46, 47]. However, the reason for the different shape of calcium carbonate on samples W2 and W3 was not clear now. Though composition of C-S-H was similar with that in $\mathrm{W} 2$, the $\mathrm{Ca} / \mathrm{Si}$ ratio decreased further. The highest, lowest and average $\mathrm{Ca} / \mathrm{Si}$ ratio of $\mathrm{C}-\mathrm{S}-\mathrm{H}$ in sample W3 were1.82, 0.27 and 0.95 . The content of C in surface of substrate also increased further after W3 treatment, indicating more carbonation occurred on the surface. According to the result of SEM observation, the modules of waterglass also affected morphology and microstructure of surface.

The SEM images of external surface of sample treated with sodium fluorosilicate are shown in Fig. 10. The specimen surface was denser and covered by tiny particles. In Fig. 10 (b), it could be found that the particles were 1-5 $\mu \mathrm{m}$ tetrahedron crystals. According to the result of EDX analyses at Points 1-3, the tiny particles had same chemical composition with the needle-like crystal in sample $\mathrm{W} 3: \mathrm{CaCO}_{3}$. The amorphous phase formed on surface of SF did not show obvious different from that in the control sample. However, the EDX analyses (Points 4-11) showed that the $\mathrm{Ca} / \mathrm{Si}$ ratio was slightly lower than sample without treatment. The mean $\mathrm{Ca} / \mathrm{Si}$ ratio of $\mathrm{C}-\mathrm{S}-\mathrm{H}$ was 1.52 . The highest $\mathrm{Ca} / \mathrm{Si}$ ratio of amorphous product within the region was 2.54, and the lowest ratio was 0.5 .

Fig. 11 presents the SEM images of external surface of the mortar sample with the combined treatment of waterglass and sodium fluorosilicate. It could find that the specimen surface was very smooth and dense at a magnification of 2000. Even at a magnification of 
5000, there was not open pores though some micro crack could be seen. The pore-blocking effect of the combined treatment of waterglass and sodium fluorosilicate was much significant than other treatment methods. In addition, there were some small particles which were silica gel on the surface. The EDX analyses were randomly conducted at eight different points on the surface. The results showed that the $\mathrm{Ca} / \mathrm{Si}$ ratio was much lower than samples without treatment and with other inorganic surface treatments. The mean $\mathrm{Ca} / \mathrm{Si}$ ratio decreased to 0.64 after combined treatment of waterglass and sodium fluorosilicate. The highest $\mathrm{Ca} / \mathrm{Si}$ ratio in sample SF-W2 was 1.2, and the lowest ratio was 0.3.

\section{Discussion}

\subsection{Interactions between magnesium fluorosilicate and cement paste}

Though the mechanism of magnesium fluorosilicate was not reported before, it was postulated that magnesium fluorosilicate would react with calcium hydroxide in cement paste as equation (1), which was believe as the mechanism of magnesium fluorosilicate surface treatment [5]. Observation in SEM found that the surface of matrix became denser after magnesium fluorosilicate treatment. In addition, the FT-IR and EDX results showed that the gel content, especially the silica gel content, increased after magnesium fluorosilicate treatment. These results supported that the magnesium fluorosilicate treatment could generated silica gel which could react with $\mathrm{Ca}(\mathrm{OH})_{2}$ and block capillary pore in surface layer as equation (2). However, the surface of mortar treated with magnesium fluorosilicate did not found $\mathrm{CaF}_{2}$ and $\mathrm{MgF}_{2}$, while there was large amount of cubic crystals of $\mathrm{KMgF}_{3}$. Complex fluoride $\mathrm{KMgF}_{3}$, with a typical cubic perovskite structure, has several advantages, such as high hardness, good homogenous optics, and high thermal stability etc. [48, 49]. $\mathrm{KMgF}_{3}$ would also play an important role in the protective effect of magnesium fluorosilicate surface treatment. In fact, the magnesium fluorosilicate did not significantly reduce the calcium hydroxide content according to the result of TGA. The solution of magnesium fluorosilicate is both mild acids and cannot react with carbon dioxide directly, thus magnesium fluorosilicate would not accelerate carbonation as other inorganic surface treatment agents. The result indicated that the magnesium fluorosilicate only partially react with $\mathrm{Ca}(\mathrm{OH})_{2}$ but also react with $\mathrm{K}^{+}$. However, as the content of $\mathrm{K}_{2} \mathrm{O}$ was very low in the cement past, the resource of the 
$\mathrm{K}^{+}$need further investigation. Some researchers investigated effect of magnesium fluorosilicate when added in fresh cement paste. Their results showed that the magnesium fluorosilicate could retard the hydration of cement particles, while increased the amount of and $\mathrm{Ca}(\mathrm{OH})_{2}[50,51]$.

$$
\begin{gathered}
2 \mathrm{MgSiF}_{6}+\mathrm{Ca}(\mathrm{OH})_{2} \rightarrow \mathrm{CaF}_{2}+\mathrm{MgF}_{2}+\mathrm{SiO}_{2} \cdot \mathrm{nH}_{2} \mathrm{O}(\mathrm{Gels}) \\
\mathrm{SiO}_{2} \cdot \mathrm{nH}_{2} \mathrm{O}+\mathrm{Ca}(\mathrm{OH})_{2} \rightarrow \mathrm{CaSiO}_{3} \cdot(\mathrm{n}+1) \mathrm{H}_{2} \mathrm{O}
\end{gathered}
$$

\subsection{Interactions between waterglass and cement paste}

The treatment of waterglass could significantly reduce the content of $\mathrm{Ca}(\mathrm{OH})_{2}$, while increased the content of $\mathrm{CaCO}_{3}$ and gel products. According to these results, the interaction between waterglass and cement paste can be concluded as following aspects. (1) The waterglass could react with $\mathrm{Ca}(\mathrm{OH})_{2}$ and form more C-S-H gel which had lower $\mathrm{Ca} / \mathrm{Si}$ ratio, as equation (3)[6]. (2) The waterglass could react with carbon dioxide easier than that of $\mathrm{Ca}(\mathrm{OH})_{2}$ and C-S-H $[52,53]$. The $\Delta \mathrm{G}^{0}{ }_{298}$ for the carbonation of $\mathrm{Ca}(\mathrm{OH})_{2}$, and C-S-H are $74.75 \mathrm{~kJ} / \mathrm{mol}$, - $74.7 \mathrm{~kJ} / \mathrm{mol}$ [23], while the $\Delta \mathrm{G}^{0}{ }_{298}$ for carbonation of waterglass with modulus of 2 and 3 are -375.03 and $-428.07 \mathrm{~kJ} / \mathrm{mol}$, much lower than the above carbonation, as shown in equations (4-7). The carbonation of waterglass generated silica gel with could block pores. However, it is difficult to know the exact amount of waterglass that react with $\mathrm{CO}_{2}$ and that react with $\mathrm{Ca}(\mathrm{OH})_{2}$. Moreover, the waterglass reduced the $\mathrm{Ca} / \mathrm{Si}$ ratio of $\mathrm{C}-\mathrm{S}-\mathrm{H}$ gel which further increased the carbonation rate of C-S-H [53].

$$
\begin{gathered}
\mathrm{Na}_{2} \mathrm{O} \cdot \mathrm{nSiO}_{2}+\mathrm{Ca}(\mathrm{OH})_{2} \rightarrow \mathrm{CaO} \cdot \mathrm{nSiO}_{2} \cdot \mathrm{xH}_{2} \mathrm{O}(\mathrm{Gels})+2 \mathrm{NaOH} \\
\mathrm{Ca}(\mathrm{OH})_{2}+\mathrm{H}_{2} \mathrm{O}+\mathrm{CO}_{2} \rightarrow \mathrm{CaCO}_{3}+2 \mathrm{H}_{2} \mathrm{O} \quad \Delta \mathrm{G}_{298}^{0}=-74.75 \mathrm{~kJ} / \mathrm{mol} \\
3 \mathrm{CaO} \cdot 2 \mathrm{SiO}_{2} \cdot 3 \mathrm{H}_{2} \mathrm{O}+3 \mathrm{H}_{2} \mathrm{CO}_{3} \rightarrow 3 \mathrm{CaCO}_{3}+2 \mathrm{SiO}_{2}+6 \mathrm{H}_{2} \mathrm{O} \quad \Delta \mathrm{G}_{298}^{0}=-74.70 \mathrm{~kJ} / \mathrm{mol} \\
2 \mathrm{NaO} \cdot 2 \mathrm{SiO}_{2}+\mathrm{CO}_{2}+4 \mathrm{H}_{2} \mathrm{O} \rightarrow \mathrm{Na}_{2} \mathrm{CO}_{3}+4 \mathrm{H}_{2} \mathrm{SiO}_{3} \quad \Delta \mathrm{G}_{298}^{0}=-375.03 \mathrm{~kJ} / \mathrm{mol} \\
2 \mathrm{NaO} \cdot 3 \mathrm{SiO}_{2}+\mathrm{CO}_{2}+6 \mathrm{H}_{2} \mathrm{O} \rightarrow \mathrm{Na}_{2} \mathrm{CO}_{3}+6 \mathrm{H}_{2} \mathrm{SiO}_{3} \quad \Delta \mathrm{G}_{298}^{0}=-428.07 \mathrm{~kJ} / \mathrm{mol}
\end{gathered}
$$

The W2 treatment worked more efficiently at early ages, while the effect of W3 treatment was more significant at 28 days. The reason was that the osmotic pressure increased with the viscosity of waterglass solution which increased with the modulus [54]. Therefore, waterglass with modulus of 3 could not deeply penetrate into concrete as waterglass with modulus of 2 at early ages. Waterglass with modulus of 3 would continuously penetrate into 
concrete with increasing time, and blocked more pores beneath the surface layer because of its high silica content. However, longer time in penetration means that it has more time to react with $\mathrm{CO}_{2}$, which is reason for more calcium carbonation formed on the surface of W3.

\subsection{Interactions between sodium fluorosilicate and cement paste}

The application of sodium fluorosilicate in cement and concrete industry is limited. Li et al [51] added it in hybrid modified cement mortar to improve long-term sulphuric acid resistance. Recently, sodium fluorosilicate was proved to have a promising ability in improving the effect of waterglass surface treatment [19].

Similar with waterglass, the sodium fluorosilicate treatment could also reduce the content of calcium hydroxide, while increased the content of $\mathrm{CaCO}_{3}$ and gel products. Sodium fluorosilicate could react with $\mathrm{Ca}(\mathrm{OH})_{2}$ as following chemical equation [21].The solution of sodium fluorosilicate are mild acids which cannot react with carbon dioxide directly, but it could reduce the content of $\mathrm{Ca}(\mathrm{OH})_{2}$ and showed significant effects on $\mathrm{CaCO}_{3}$ content. The reason is that sodium fluorosilicate could react with $\mathrm{Ca}(\mathrm{OH})_{2}$ thus accelerate the carbonation of cement paste. As both the consumption of $\mathrm{Ca}(\mathrm{OH})_{2}$ and generation $\mathrm{CaCO}_{3}$ can reduce the porosity of in cement-based materials, sodium fluorosilicate can make the surface more denser. However, though the surfaces of samples W2, W3, and SF were coved with many $\mathrm{CaCO}_{3}$ particles, morphology of those $\mathrm{CaCO}_{3}$ particles were significantly different with each other. The reason need further investigation. It postulated that the carbonation of C-S-H gel would change with $\mathrm{Ca} / \mathrm{Si}$ ratio and environment [55-58].

$$
\mathrm{Na}_{2} \mathrm{SiF}_{6}+6 \mathrm{Ca}(\mathrm{OH})_{2} \rightarrow 3 \mathrm{NaF}+2 \mathrm{NaOH}+\mathrm{CaO} \cdot \mathrm{nSiO}_{2} \cdot \mathrm{xH}_{2} \mathrm{O}(\text { Gels })
$$

\subsection{Interactions between the combined treatment and cement paste}

Previous studied found that the combined treatment of waterglass and sodium fluorosilicate could reduce the water permeability and improve the carbonation resistance of concrete $[19,20]$. The sodium fluorosilicate is one of the curing agents of waterglass. It can accelerate the hardening of waterglass, forming silica gel and fluoride as equation (9). The products of interaction between waterglass and sodium fluorosilicate has thermal stability, good durability in different acid solutions and water [22, 59].

$$
2\left(\mathrm{Na}_{2} \mathrm{O} \cdot \mathrm{nSiO}_{2}\right)+\mathrm{Na}_{2} \mathrm{SiF}_{6}+2(\mathrm{n}+1) \mathrm{H}_{2} \mathrm{O} \rightarrow(2 \mathrm{n}+1) \mathrm{SiO}_{2} \cdot \mathrm{xH}_{2} \mathrm{O}+6 \mathrm{NaF}
$$


In the same time, reaction (6) and (8) would also occur in sample SF-W2. After the combined treatment of waterglass and sodium fluorosilicate, the calcium hydroxide on surface layer was the lowest one compared with other surface treatment. This indicated that both the waterglass and sodium fluorosilicate attributed to the consumption of $\mathrm{Ca}(\mathrm{OH})_{2}$. The result of FT-IR showed that the surface paste treated with the combined treatment had more gel products. In addition, $\mathrm{CaCO}_{3}$ content in the sample treated with combined treatment was lower than the sample treated with waterglass and sodium fluorosilicate alone. There are two possible reasons: (1) the addition of $\mathrm{Na}_{2} \mathrm{SiF}_{6}$ accelerated the harded of waterglass, which avoid the carbonation of waterglass; (2) the silica gel formed by the interaction of waterglass and $\mathrm{Na}_{2} \mathrm{SiF}_{6}$ inhibited the diffusion of carbon dioxide.

\section{Conclusion}

The changes in microstructure and phases after inorganic surface treatments on hydrated Portland cement pastes and mortars are investigated. Based on the result and discussion, following conclusions can be drawn:

(1) The magnesium fluorosilicate surface treatment agent only had a slight impact on the content of $\mathrm{Ca}(\mathrm{OH})_{2}$, and would not accelerate the carbonation of surface layer. The formation of silica gel and cubic crystal of $\mathrm{KMgF}_{3}$ made the microstructure of surface paste denser. The mechanism of magnesium fluorosilicate may not be limited on the reaction with $\mathrm{Ca}(\mathrm{OH})_{2}$, it could also react with $\mathrm{K}^{+}$.

(2) The waterglass surface treatment could not only significantly reduce the content of $\mathrm{Ca}(\mathrm{OH})_{2}$, but also increased the content of $\mathrm{CaCO}_{3}$ and gel products. In addition, it could reduce the $\mathrm{Ca} / \mathrm{Si}$ ratio of hardened cement in surface layer. Moreover, the module of waterglass also affected the chemical composition of C-S-H gel and morphology of external surface.

(3) The sodium fluorosilicate could accelerate the hardening of waterglass and show impact on the chemical composition and morphology of surface layer. It reduced the $\mathrm{Ca}(\mathrm{OH})_{2}$ and accelerated the carbonation, while could not significantly increase the total gel content.

(4) The pore blocking effect of the combined treatment of waterglass and sodium fluorosilicate was much significant than other treatment methods. The combined treatment 
could not only significantly reduce the content of $\mathrm{Ca}(\mathrm{OH})_{2}$, while did not significantly increased the content of $\mathrm{CaCO}_{3}$.

\section{Acknowledgement}

Financially supported by the National Science Foundation of China under project Nos. U1305243 and 51378196.

\section{References:}

[1] Kreijger PC, The skin of concrete composition and properties. Matériaux et Construction 1984, 17(4): 275-283.

[2] Long AE, Henderson GD, Montgomery FR, Why assess the properties of near-surface concrete? Construction and Building Materials 2001; 15(2): 65-79.

[3] Uni, EN 1504-2. Products and systems for the protection and repair of concrete structures. Definitions, requirements, quality control and evaluation of conformity - Part 2: surface protection systems for, concrete; 2004.

[4] Dai JG, Akira Y, Wittmann FH, Yokota H, Zhang P, Water repellent surface impregnation for extension of service life of reinforced concrete structures in marine environments: the role of cracks. Cement and Concrete Composites 2010; 32(2): 101-109.

[5] Bertolini L, Elsener B, Pedeferri P, Redaelli E, Polder RB, Corrosion of steel in concrete: prevention, diagnosis, repair. John Wiley \& Sons 2013.

[6] Moradllo MK, Shekarchi M, Hoseini M, Time-dependent performance of concrete surface coatings in tidal zone of marine environment. Construction and Building Materials 2012; 30: 198-205.

[7] Li H, Yi Z, Xie Y, Progress of silane impregnating surface treatment technology of concrete structure. Materials review 2012; 26(3): 120-125

[8] Pigino B, Leemann A, Franzoni E, Lura P, Ethyl silicate for surface treatment of concrete-Part II: Characteristics and performance. Cement and Concrete Composites 2012; 34(3): 313-321.

[9] Dang Y, Xie N, Kessel A, McVey E, Pace A, Shi X, Accelerated laboratory evaluation of surface treatments for protecting concrete bridge decks from salt scaling. Construction and 
Building Materials 2014; 55(0): 128-135.

[10] Medeiros M, Helene P, Efficacy of surface hydrophobic agents in reducing water and chloride ion penetration in concrete. Materials and Structures 2008; 41(1): 59-71.

[11] Medeiros MH, Helene P, Surface treatment of reinforced concrete in marine environment: Influence on chloride diffusion coefficient and capillary water absorption. Construction and Building Materials 2009; 23(3): 1476-1484.

[12] Jones MR, Dhir RK, Gill JP, Concrete surface treatment: effect of exposure temperature on chloride diffusion resistance. Cement and Concrete Research 1995; 25(1): 197-208.

[13] Levi M, Ferro C, Regazzoli D, Dotelli G, Comparative evaluation method of polymer surface treatments applied on high performance concrete. Journal of Materials Science 2002; 37(22): 4881-4888.

[14] Thompson JL, Silsbee MR, Gill PM, Scheetz BE, Characterization of silicate sealers on concrete. Cement and Concrete Research 1997; 27(10):1561-1567.

[15] Kagi DA, Ren KB, Reduction of water absorption in silicate treated concrete by post-treatment with cationic surfactants. Building and Environment 1995; 30(2):237-243.

[16] Franzoni E, Varum H, Natali ME, Bignozzi MC, Melo J, Rocha L, Pereira E, Improvement of historic reinforced concrete/mortars by impregnation and electrochemical methods. Cement and Concrete Composites 2014; 49(0): 50-58.

[17] Ibrahim M, Al-Gahtani AS, Maslehuddin M, Dakhil FH, Use of surface treatment materials to improve concrete durability. Journal of Materials in Civil Engineering 1999; 11(1):36-40.

[18] Franzoni E, Pigino B, Pistolesi C, Ethyl silicate for surface protection of concrete: Performance in comparison with other inorganic surface treatments. Cement and Concrete Composites 2013; 44(0): 69-76.

[19] Pan X, Shi C, Jia L, Zhang J, Wu L, Effect of Inorganic Surface Treatment on Air Permeability of Cement-Based Materials. Journal of Materials in Civil Engineering 2015: 04015145.

[20] Jia L, Shi C, Pan X , Zhang J, Wu L, Effects of inorganic surface treatment on water permeability of cement-based materials. Cement and Concrete Composites 2016; 67: 85-92.

[21] Singh M, Influence of blended gypsum on the properties of Portland cement and Portland 
slag cement. Cement and Concrete Research 2000; 30(8): 1185-1188.

[22] Voitovich VA. Curing agents of silicate based adhesives. Polymer Science. Series D, 2010; 3(3), 174-176.

[23] Zhang Z, Wang H, Provis JL, Quantitative study of the reactivity of fly ash in geopolymerization by FTIR. Journal of Sustainable Cement-Based Materials 2012; 1(4): 154-166.

[24] Wu G, Fourier transform infrared spectroscopy technology and its application. Scientific and technological literature press, 1994.

[25] Gonen T, Yazicioglu S, The influence of compaction pores on sorptivity and carbonation of concrete. Construction and Building Materials 2007; 21(5): 1040-1045.

[26] Zhang J, Shi C, Li Y, Pan X, Poon CS, Xie Z, Performance Enhancement of Recycled Concrete Aggregates through Carbonation. Journal of Materials in Civil Engineering 2015: 04015029.

[27] Li G, Xiong G, Yin Y, The physical and chemical effects of long-term sulphuric acid exposure on hybrid modified cement mortar. Cement and Concrete Composites 2009; 31(5): 325-330.

[28] Ylmén R, Jäglid U, Steenari BM, Panas I, Early hydration and setting of Portland cement monitored by IR, SEM and Vicat techniques. Cement and Concrete Research 2009; 39(5): 433-439.

[29] Yu P, Kirkpatrick RJ, Poe B, McMillan PF, Cong X, Structure of calcium silicate hydrate (C-S-H): Near-, Mid-, and Far-infrared spectroscopy. Journal of the American Ceramic Society 1999; 82(3):742-748.

[30] Ylmén R, Wadsö L, Panas I, Insights into early hydration of Portland limestone cement from infrared spectroscopy and isothermal calorimetry. Cement and Concrete Research 2010; 40(10): 1541-1546.

[31] Taylor, HF, Cement chemistry. Thomas Telford, 1997.

[32] García-Lodeiro I, Fernández-Jiménez A, Blanco MT, Palomo A, FTIR study of the sol-gel synthesis of cementitious gels: C-S-H and N-A-S-H. Journal of Sol-Gel Science and Technology 2008; 45(1):63-72.

[33] Lodeiro IG, Macphee DE, Palomo A, Fernández-Jiménez A, Effect of alkalis on fresh 
C-S-H gels. FTIR analysis. Cement and Concrete Research 2009; 39(3): 147-153.

[34] Hong S, Glasser FP, Alkali binding in cement pastes: Part I. The C-S-H phase. Cement and Concrete Research 1999; 29(12): 1893-1903.

[35] Black L, Garbev K, Gee I, Surface carbonation of synthetic CSH samples: A comparison between fresh and aged CSH using X-ray photoelectron spectroscopy. Cement and Concrete Research 2008, 38(6): 745-750.

[36] Richardson IG, The nature of CSH in hardened cements. Cement and Concrete Research 1999; 29(8): 1131-1147.

[37] Chen JJ, Thomas JJ, Taylor HF, Jennings HM, Solubility and structure of calcium silicate hydrate. Cement and Concrete Research 2004; 34(9):1499-1519.

[38] Shi Z, Lothenbach B, Geiker MR, Kaufmann J, Leemann A, Ferreiro S, Skibsted J, Experimental studies and thermodynamic modeling of the carbonation of Portland cement, metakaolin and limestone mortars. Submitted to Cement and Concrete Research 2015.

[39] Garboczi EJ, Bentz DP, Digitised simulation of mercury intrusion porosimetry. Ceram. Trans 1990; 16:365-380.

[40] Pourbeik P, Beaudoin JJ, Alizadeh R, Raki L, Mechanical property-porosity relationships of layered calcium silicate hydrate phases. Materials and Structures 2013; 46(9): 1489-1495. [41] Thomas JJ, Chen JJ, Allen AJ, Jennings HM, Effects of decalcification on the microstructure and surface area of cement and tricalcium silicate pastes. Cement and Concrete Research 2004; 34(12): 2297-2307.

[42] Morandeau A, Thiéry M, Dangla P, Impact of accelerated carbonation on OPC cement paste blended with fly ash. Cement and Concrete Research 2015; 67: 226-236.

[43] Grangeona S, Clareta F, Lerougea C, Warmontb F, Satoc T, Anrakuc S, Numakod C, Linarde Y, Lansonf B, On the nature of structural disorder in calcium silicate hydrates with a calcium/silicon ratio similar to tobermorite. Cement and Concrete Research 2013; 52(0):31-37.

[44] Mendoza O, Giraldo C, Camargo SS, Tobón JI, Structural and nano-mechanical properties of Calcium Silicate Hydrate (C-S-H) formed from alite hydration in the presence of sodium and potassium hydroxide. Cement and Concrete Research 2015, 74(0): 88-94.

[45]Blanc P, Bourbon X, Lassin A, Gaucher EC, Chemical model for cement-based materials: 
Temperature dependence of thermodynamic functions for nanocrystalline and crystalline C-S-H phases. Cement and Concrete Research 2010; 40(6): 851-866.

[46] Chang J, Fang Y, Li Y, Effects of Calcium to Silicon Ratios on Accelerating Carbonation of Calcium Silicate Hydrate. Journal of the Chinese Ceramic Society 2014; 11: 1377-1382.

[47]Black L, Breen C, Yarwood J, Garbev K, Stemmermann P, Gasharova B, Structural features of C-S-H (I) and its carbonation in air-a Raman spectroscopic study. Part II: carbonated phases. Journal of the American Ceramic Society 2007; 90(3): 908-917.

[48] Hua R, Jia Z, Xie D, Shi C, Solvothermal synthesis of the complex fluorides $\mathrm{KMgF}_{3}$ and $\mathrm{KZnF}_{3}$ with the Perovskite structures. Materials research bulletin 2002; 37(6):1189-1195.

[49] Cao M, Wang Y, Qi Y, Guo C, Hu C, Synthesis and characterization of $\mathrm{MgF}_{2}$ and $\mathrm{KMgF}_{3}$ nanorods. Journal of Solid State Chemistry 2004; 177(6):2205-2209.

[50] Berger RL, McGregor JD. Influence of admixtures on the morphology of calcium hydroxide formed during tricalcium silicate hydration. Cement and Concrete Research 1972 2(1), 43-55.

[51] Li W, Wang Y, Wang GM, Shi Y, Wang ZM. Research on Using Fluorosilicate for the Enhanced Performance of Concrete. Special Publication 2015; 303, 293-300.

[52] Visser J, Influence of the carbon dioxide concentration on the resistance to carbonation of concrete. Construction and Building Materials 2013; 67: 8-13.

[53] Groves GW, Brough A. Richardson IG, Dobson CM, Progressive changes in the structure of hardened $\mathrm{C}_{3} \mathrm{~S}$ cement pastes due to carbonation. Journal of the American Ceramic Society 1991; 74(11):2891-2896.

[54] Li G, Xiong G, Yin Y. The physical and chemical effects of long-term sulphuric acid exposure on hybrid modified cement mortar. Cement and Concrete Composites, 2009; 31(5), $325-330$

[55] Black L, Garbev K, Gee I, Surface carbonation of synthetic CSH samples: A comparison between fresh and aged CSH using X-ray photoelectron spectroscopy. Cement and Concrete Research 2008; 38(6): 745-750.

[56] Garbev K, Stemmermann P, Black L, Breen C, Yarwood J, Gasharova B, Structural features of C-S-H (I) and its carbonation in air-a Raman spectroscopic study. Part I: fresh phases. Journal of the American Ceramic Society 2007; 90(3): 900-907. 
[57] Borges PH, Costa JO, Milestone NB, Lynsdale CJ, Streatfield RE, Carbonation of CH and $\mathrm{C}-\mathrm{S}-\mathrm{H}$ in composite cement pastes containing high amounts of BFS. Cement and Concrete Research 2010; 40(2): 284-292.

[58] Slegers PA, Rouxhet PG, Carbonation of the hydration products of tricalcium silicate. Cement and Concrete Research 1976; 6(3): 381-388.

[59] Zellmann HD, Kaps C. Chemically Modified Water - Glass Binders for Acid - Resistant Mortars. Journal of the American Ceramic Society, 2006; 89(4), 1369-1372. 


\section{LIST OF TABLES}

Table 1. Chemical compositions of the P.I. 42.5 Portland cement.

Table 2. Grading of sand.

Table 3. Chemical composition and physical properties of the waterglass.

Table 4. Surface treatment on cutting surface of the mortar and paste cylinders.

Table 5 Composition of surface layer on UNTR mortar specimen (Atomic \%).

Table 6 Composition of surface layer on MF mortar specimen (Atomic \%).

Table 7 Composition of surface layer on W2 mortar specimen (Atomic \%).

Table 8 Composition of surface layer on W3 mortar specimen (Atomic \%).

Table 9 Composition of surface layer on SF mortar specimen (Atomic \%).

Table 10 Composition of surface layer on SF-W2 mortar specimen (Atomic \%). 
Table 1. Chemical compositions of the P.I. 42.5 Portland cement.

\begin{tabular}{ccccccccccc}
\hline & $\mathrm{SiO}_{2}$ & $\mathrm{Al}_{2} \mathrm{O}_{3}$ & $\mathrm{Fe}_{2} \mathrm{O}_{3}$ & $\mathrm{CaO}$ & $\mathrm{MgO}$ & $\mathrm{K}_{2} \mathrm{O}$ & $\mathrm{Na}_{2} \mathrm{O}$ & $\mathrm{SO}_{3}$ & $\mathrm{Na}_{2} \mathrm{O}_{\text {eq }}$ & $\mathrm{LOI}$ \\
\hline $\begin{array}{c}\text { Percentage } \\
\text { (wt. \%) }\end{array}$ & 21.91 & 5.30 & 3.67 & 64.5 & 1.51 & 0.62 & 0.19 & 2.03 & 0.59 & 2.49 \\
\hline
\end{tabular}


Table 2. Grading of sand.

\begin{tabular}{ccccccc}
\hline Size $(\mathrm{mm})$ & 5 & 2.5 & 1.25 & 0.63 & 0.315 & 0.16 \\
\hline Cumulative retained of sand (wt. \%) & 8.0 & 21.2 & 36.7 & 56.5 & 89.0 & 98.6 \\
\hline
\end{tabular}


Table 3. Chemical composition and physical properties of the waterglass.

\begin{tabular}{ccccc}
\hline Modulus & $\mathrm{Na}_{2} \mathrm{O}$ (wt. \%) & $\mathrm{SiO}_{2}$ (wt. \%) & Baume degree $\left({ }^{\circ}\right.$ Bé) & Density $\left(\mathrm{kg} / \mathrm{m}^{3}\right)$ \\
\hline 3 & 9.05 & 26.5 & 38.4 & 1369 \\
2 & 12.9 & 25.0 & 44.1 & 1440 \\
\hline
\end{tabular}


Table 4. Surface treatment on cutting surface of the mortar and paste cylinders.

\begin{tabular}{ccc}
\hline Specimen & Surface treatment & $\begin{array}{c}\text { Treatment } \\
\text { number }\end{array}$ \\
\hline UNTR & no treatment & 0 \\
MF & 30\% magnesium fluorosilicate solutions & 4 \\
W2 & waterglass with modulus of 2 & 4 \\
W3 & waterglass with modulus of 3 & 4 \\
SF & 2\% sodium fluorosilicate solutions & 4 \\
SF-W2 & 2\% sodium fluorosilicate solutions + waterglass with modulus of 2 & $4+4$ \\
\hline
\end{tabular}


Table 5 Composition of surface layer on UNTR mortar specimen (Atomic \%).

\begin{tabular}{cccccccc}
\hline Point & Ca & Si & C & O & Mg & Na & K \\
\hline 1 & 20.87 & 1.69 & 23.58 & 47.34 & 0.92 & 0.13 & 1.60 \\
2 & 20.98 & 2.58 & 24.06 & 48.08 & 0.73 & 0.08 & 0.61 \\
3 & 25.60 & 1.23 & 19.07 & 51.94 & 0.24 & 0.10 & 0.24 \\
\hline 4 & 25.87 & 8.44 & 14.58 & 47.34 & 0.22 & 0.00 & 1.60 \\
5 & 23.27 & 11.20 & 10.10 & 50.69 & 0.34 & 0.12 & 0.35 \\
6 & 21.98 & 9.55 & 15.64 & 49.41 & 0.21 & 0.38 & 0.45 \\
7 & 21.37 & 9.06 & 17.49 & 48.35 & 0.12 & 0.21 & 0.89 \\
8 & 20.96 & 12.18 & 15.64 & 49.22 & 0.25 & 0.17 & 0.94 \\
9 & 20.34 & 14.29 & 14.88 & 45.89 & 0.67 & 0.15 & 1.52 \\
10 & 19.53 & 15.69 & 12.45 & 48.31 & 0.42 & 0.06 & 0.63 \\
11 & 17.75 & 14.14 & 16.74 & 49.26 & 0.64 & 0.21 & 1.00 \\
Avg. & 21.38 & 11.82 & 14.69 & 48.56 & 0.37 & 0.16 & 0.92 \\
\hline
\end{tabular}


Table 6 Composition of surface layer on MF mortar specimen (Atomic \%).

\begin{tabular}{cccccccc}
\hline Point & $\mathrm{Ca}$ & $\mathrm{Si}$ & $\mathrm{C}$ & $\mathrm{O}$ & $\mathrm{Mg}$ & $\mathrm{F}$ & $\mathrm{K}$ \\
\hline 1 & 0.75 & 0.98 & 14.43 & 1.45 & 17.42 & 48.54 & 15.61 \\
2 & - & 0.55 & 17.86 & - & 18.93 & 48.23 & 14.43 \\
3 & - & 0.35 & 20.74 & - & 17.64 & 48.13 & 13.14 \\
\hline 4 & 1.08 & 8.68 & 11.45 & 18.35 & 12.12 & 34.99 & 11.26 \\
5 & 0.57 & 6.65 & 13.67 & 17.24 & 12.69 & 36.38 & 11.39 \\
6 & 1.43 & 4.32 & 9.43 & 15.6 & 13.62 & 39.52 & 14.38 \\
7 & 0.56 & 7.46 & 9.72 & 19.78 & 11.90 & 35.69 & 13.74 \\
\hline 8 & 4.98 & 21.15 & 6.93 & 37.29 & 6.86 & 17.02 & 5.06 \\
9 & 4.93 & 17.57 & 8.76 & 45.06 & 4.40 & 13.14 & 5.10 \\
10 & 3.71 & 21.48 & 7.38 & 42.97 & 5.47 & 10.70 & 6.51 \\
11 & 1.40 & 23.29 & 9.69 & 31.55 & 6.3 & 19.02 & 7.22 \\
\hline
\end{tabular}


Table 7 Composition of surface layer on W2 mortar specimen (Atomic \%).

\begin{tabular}{cccccccc}
\hline Point & $\mathrm{Ca}$ & $\mathrm{Si}$ & $\mathrm{C}$ & $\mathrm{O}$ & $\mathrm{Mg}$ & $\mathrm{Na}$ & $\mathrm{K}$ \\
\hline 1 & 16.37 & 1.47 & 29.07 & 51.2 & 0.28 & 0.51 & 0.25 \\
2 & 16.15 & 0.84 & 31.15 & 50.89 & 0.12 & 0.42 & 0.31 \\
3 & 20.62 & 0.90 & 28.38 & 48.29 & 0.22 & 0.35 & 0.42 \\
\hline 4 & 17.49 & 8.49 & 27.10 & 45.41 & 0.15 & 0.19 & 0.64 \\
5 & 16.01 & 9.88 & 19.04 & 52.02 & 0.38 & 0.67 & 1.23 \\
6 & 14.83 & 7.25 & 29.64 & 45.18 & 0.75 & 0.36 & 0.98 \\
7 & 15.28 & 7.03 & 25.06 & 48.54 & 0.59 & 0.44 & 1.04 \\
8 & 10.01 & 11.85 & 25.82 & 51.69 & 0.10 & 0.26 & 0.16 \\
9 & 8.25 & 15.25 & 25.94 & 48.15 & 0.42 & 0.34 & 0.24 \\
10 & 7.66 & 18.97 & 24.88 & 46.61 & 0.15 & 0.27 & 0.79 \\
11 & 5.58 & 16.22 & 26.37 & 49.94 & 0.28 & 0.51 & 0.13 \\
Avg. & 11.89 & 11.87 & 25.48 & 48.44 & 0.35 & 0.38 & 0.65 \\
\hline
\end{tabular}


Table 8 Composition of surface layer on W3 mortar specimen (Atomic \%).

\begin{tabular}{ccccccccc}
\hline Atomic\% & Ca & Si & C & O & Mg & Na & K \\
\hline 1 & 21.06 & 0.17 & 27.33 & 50.57 & 0.46 & 0.21 & 0.11 \\
2 & 19.55 & 0.21 & 26.93 & 52.31 & - & 0.34 & - \\
3 & 28.81 & 0.04 & 24.00 & 45.67 & 0.23 & 0.26 & 0.10 \\
\hline 4 & 21.39 & 0.27 & 25.97 & 51.20 & 0.66 & 0.27 & 0.13 \\
5 & 15.44 & 4.65 & 29.27 & 47.76 & 0.58 & 0.68 & 0.88 \\
6 & 20.28 & 02.06 & 34.56 & 41.50 & - & 0.42 & 0.76 \\
\hline 7 & 18.01 & 9.88 & 19.04 & 50.28 & 0.38 & 0.45 & 1.23 \\
8 & 14.38 & 7.90 & 28.84 & 45.01 & 0.81 & 0.28 & 1.38 \\
9 & 13.6 & 7.44 & 25.76 & 50.82 & 0.71 & 0.16 & 0.47 \\
10 & 10.97 & 11.98 & 29.36 & 45.69 & 0.27 & 0.54 & 0.24 \\
11 & 9.60 & 5.99 & 31.21 & 50.30 & 0.44 & 0.26 & 0.84 \\
12 & 9.79 & 14.99 & 29.74 & 44.31 & 0.18 & 0.31 & 0.42 \\
13 & 6.58 & 14.72 & 26.37 & 49.94 & 0.08 & 0.25 & 0.23 \\
14 & 5.43 & 19.92 & 20.10 & 52.84 & 0.13 & 0.64 & 0.22 \\
Avg. & 11.05 & 11.60 & 26.30 & 48.65 & 0.38 & 0.36 & 0.63 \\
\hline
\end{tabular}


Table 9 Composition of surface layer on SF mortar specimen (Atomic \%).

\begin{tabular}{cccccccc}
\hline Atomic\% & $\mathrm{Ca}$ & $\mathrm{Si}$ & $\mathrm{C}$ & $\mathrm{O}$ & $\mathrm{Mg}$ & $\mathrm{Na}$ & $\mathrm{K}$ \\
\hline 1 & 13.21 & 1.04 & 33.83 & 50.14 & 0.91 & 0.07 & 0.47 \\
2 & 16.57 & 2.69 & 27.99 & 50.10 & 1.13 & 0.22 & 1.06 \\
3 & 14.00 & 01.87 & 30.71 & 51.15 & 1.11 & 0.25 & 0.77 \\
\hline 4 & 26.21 & 10.3 & 17.43 & 42.97 & 0.29 & 0.31 & 0.88 \\
5 & 23.27 & 11.2 & 13.1 & 48.69 & 0.74 & 0.26 & 1.25 \\
6 & 18.75 & 12.01 & 20.02 & 45.52 & 0.33 & 0.28 & 0.32 \\
7 & 18.09 & 10.98 & 24.51 & 45.4 & 0.17 & 0.12 & 0.16 \\
8 & 15.02 & 12.01 & 22.2 & 47.8 & 0.22 & 0.18 & 1.06 \\
9 & 13.74 & 9.04 & 24.17 & 50.15 & 0.67 & 0.22 & 0.75 \\
10 & 11.87 & 9.28 & 18.55 & 56.79 & 0.24 & 0.2 & 0.69 \\
11 & 5.48 & 10.87 & 26.29 & 55.11 & 0.44 & 0.17 & 0.41 \\
Avg. & 16.55 & 10.71 & 20.78 & 49.05 & 0.39 & 0.22 & 0.69 \\
\hline
\end{tabular}


Table 10 Composition of surface layer on SF-W2 mortar specimen (Atomic \%).

\begin{tabular}{cccccccc}
\hline Atomic\% & $\mathrm{Ca}$ & $\mathrm{Si}$ & $\mathrm{C}$ & $\mathrm{O}$ & $\mathrm{Mg}$ & $\mathrm{Na}$ & $\mathrm{K}$ \\
\hline 1 & 1.28 & 30.47 & 9.93 & 55.91 & 0.59 & 0.45 & 0.3 \\
2 & 1.7 & 22.79 & 18.89 & 54.62 & - & 0.58 & 0.74 \\
3 & 3.28 & 28.47 & 7.99 & 57.91 & 0.59 & 0.43 & 0.3 \\
\hline 4 & 14.05 & 11.7 & 20.43 & 51.89 & 0.17 & 0.24 & 0.15 \\
5 & 13.37 & 11.57 & 16.41 & 55.84 & 0.67 & 0.41 & 0.47 \\
6 & 10.68 & 12.28 & 17.55 & 55.79 & 0.84 & 0.37 & 0.62 \\
7 & 8.39 & 20.76 & 15.25 & 52.73 & 0 & 0.56 & 0.37 \\
8 & 6.89 & 14.93 & 20.67 & 54.96 & 0.23 & 0.75 & 0.79 \\
9 & 5.75 & 16.01 & 23.02 & 53.52 & 0.33 & 0.36 & 0.89 \\
10 & 5.28 & 16.7 & 18.94 & 57.2 & 0.74 & 0.32 & 0.3 \\
11 & 4.09 & 11.93 & 26.07 & 55.96 & 0.2 & 0.42 & 0.49 \\
Avg. & 8.56 & 14.48 & 19.79 & 54.74 & 0.40 & 0.43 & 0.51 \\
\hline
\end{tabular}




\section{LIST OF FIGURES}

Fig. 1. Effect of inorganic surface treatments on $\mathrm{Ca}(\mathrm{OH})_{2}$ (a) and $\mathrm{CaCO}_{3}$ (b) content.

Fig. 2. Relationship between the decrease in $\mathrm{Ca}(\mathrm{OH})_{2}$ and increase in $\mathrm{CaCO}_{3}$ at 28 day (taking the UNTR sample as a reference).

Fig. 3. FT-IR spectra for surfaces of cement paste after different surface treatments.

Fig. 4. Deconvolution of the $\mathrm{Si}-\mathrm{O}$ asymmetric stretching band in $\mathrm{C}-\mathrm{S}-\mathrm{H}$ gels.

Fig. 5. Variation of the areas of deconvolved components for C-S-H gels.

Fig. 6. ESEM images of external surface of UNTR mortar sample at a magnification of 2000 (a) and at a magnification of 5000 (b).

Fig. 7. ESEM images of external surface of MF mortar sample at a magnification of 2000 (a) and at a magnification of 5000 (b).

Fig. 8. ESEM images of external surface of W2 mortar sample at a magnification of 2000 (a) and at a magnification of 10000 (b).

Fig. 9. ESEM images of external surface of W3 mortar sample at a magnification of 2000 (a) and at a magnification of 10000 (b).

Fig. 10. ESEM images of external surface of SF mortar sample at a magnification of 2000 (a) and at a magnification of 5000 (b and c).

Fig. 11. ESEM images of external surface of SF-W2 mortar sample at a magnification of 2000 (a) and at a magnification of 5000 (b). 


\section{FIGURES}
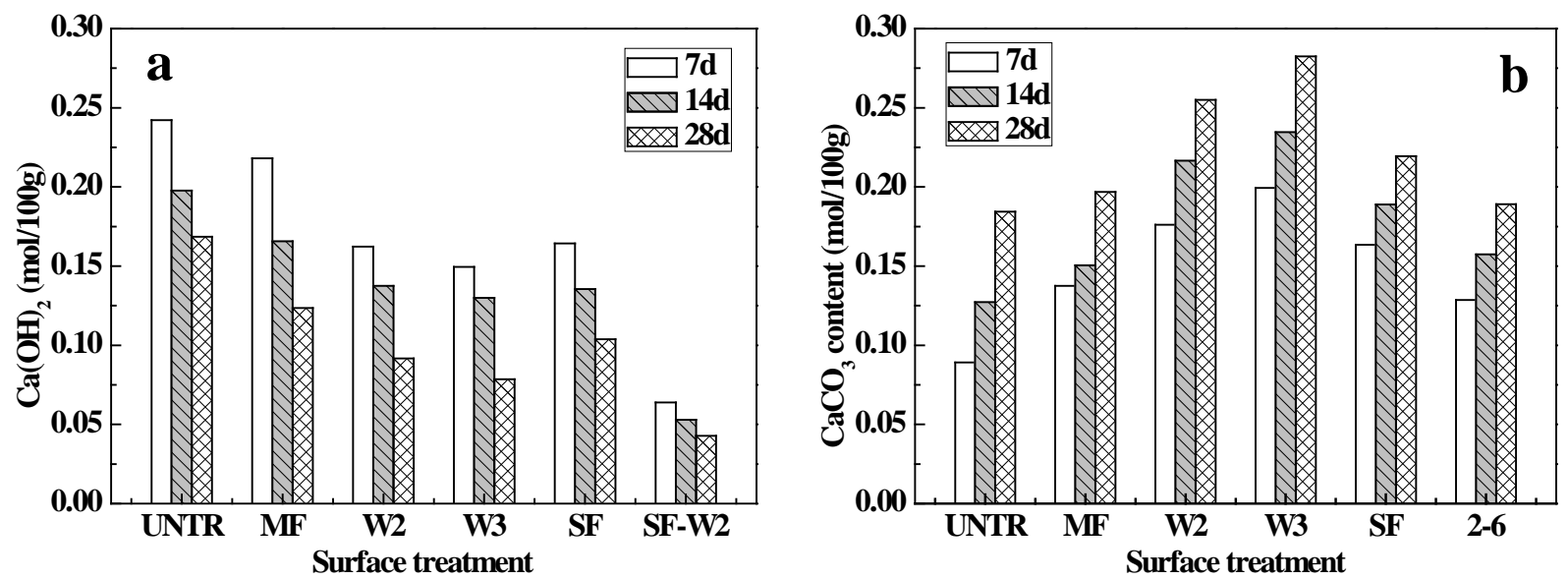

Fig. 1 Effect of inorganic surface treatments on $\mathrm{Ca}(\mathrm{OH})_{2}$ (a) and $\mathrm{CaCO}_{3}$ (b) content. 


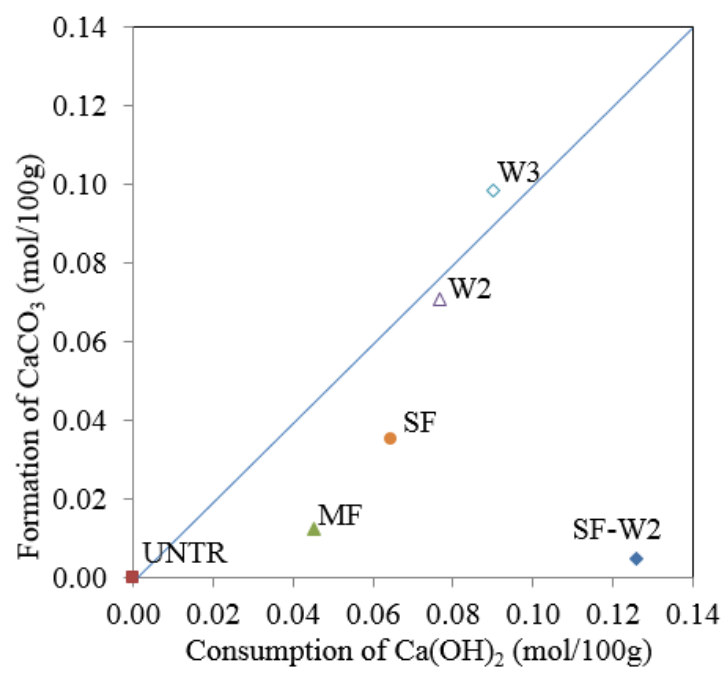

Fig. 2 Relationship between the decrease in $\mathrm{Ca}(\mathrm{OH})_{2}$ and increase in $\mathrm{CaCO}_{3}$ at 28 day (taking the UNTR sample as a reference). 


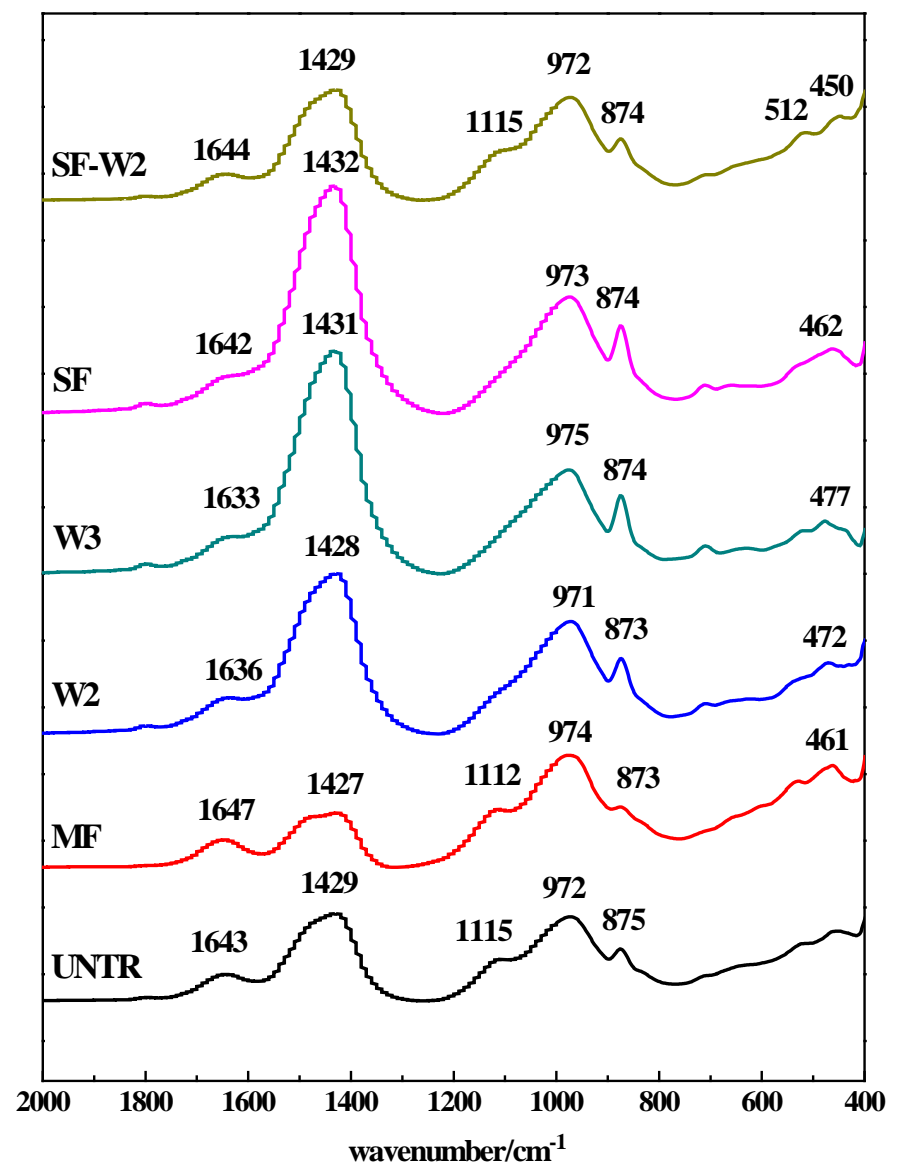

Fig. 3 FT-IR spectra for surfaces of cement paste after different surface treatments. 


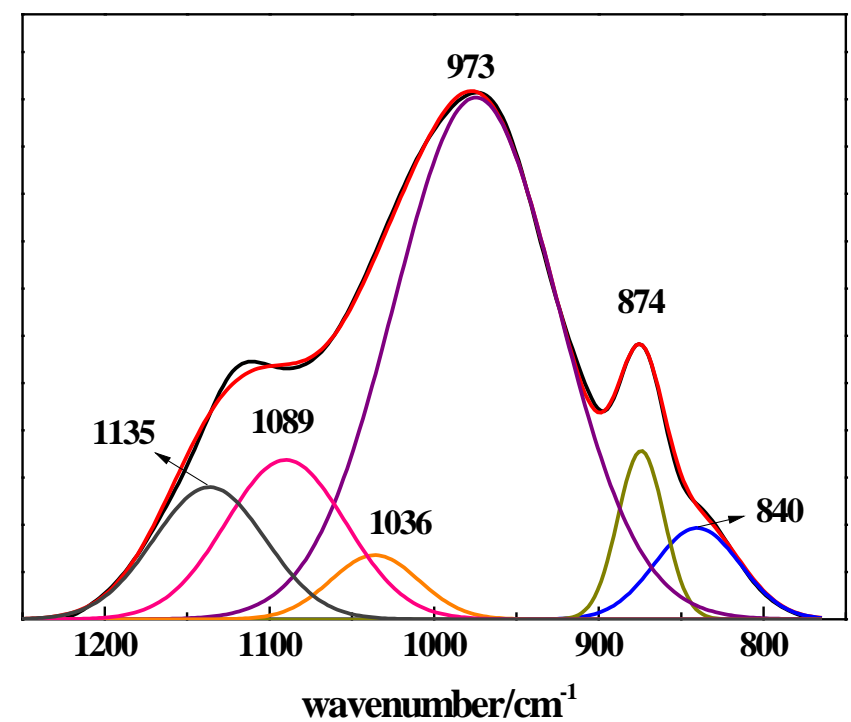

Fig. 4 Deconvolution of the $\mathrm{Si}-\mathrm{O}$ asymmetric stretching band in $\mathrm{C}-\mathrm{S}-\mathrm{H}$ gels. 


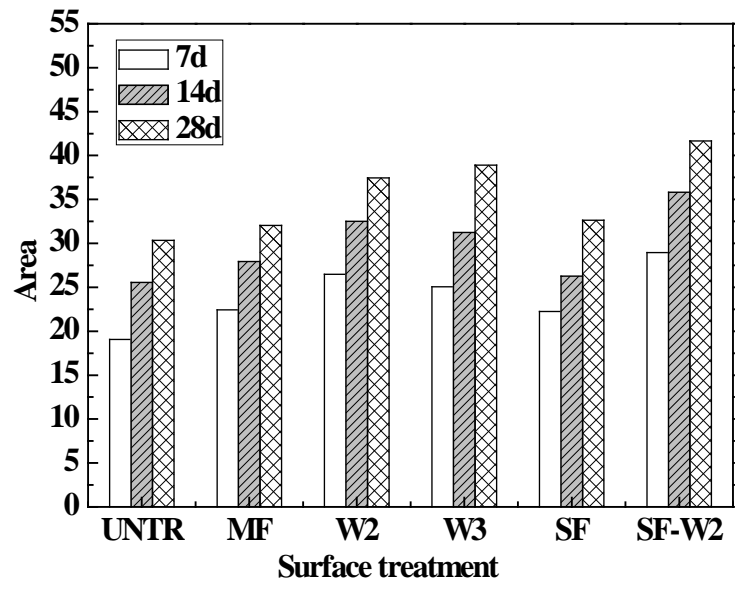

(a) Area of the band at around $973 \mathrm{~cm}^{-1}\left(\mathrm{Q}_{2}\right)$

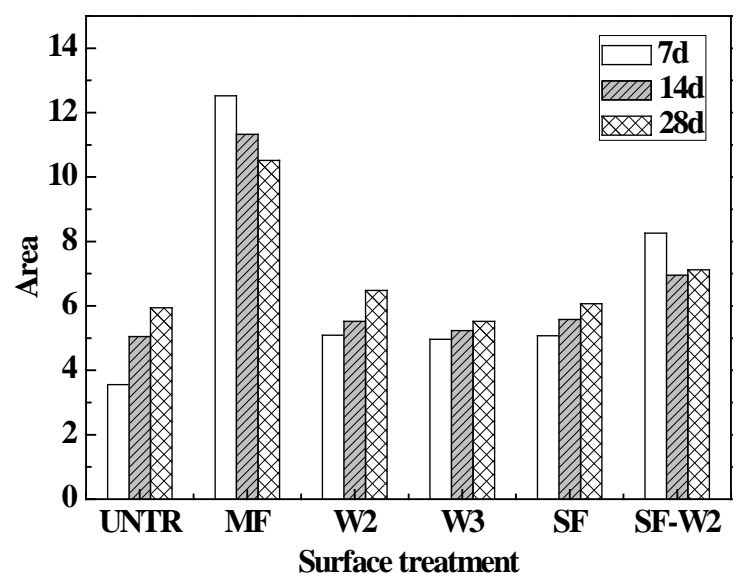

(c) Area of the band at around $1135 \mathrm{~cm}^{-1}\left(\mathrm{Q}_{4}\right)$

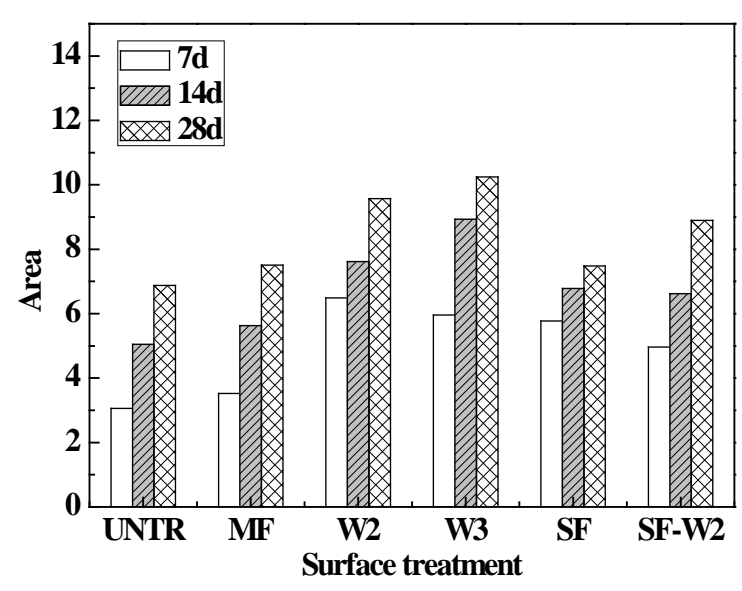

(b) Area of the band at around $1089 \mathrm{~cm}^{-1}\left(\mathrm{Q}_{3}\right)$

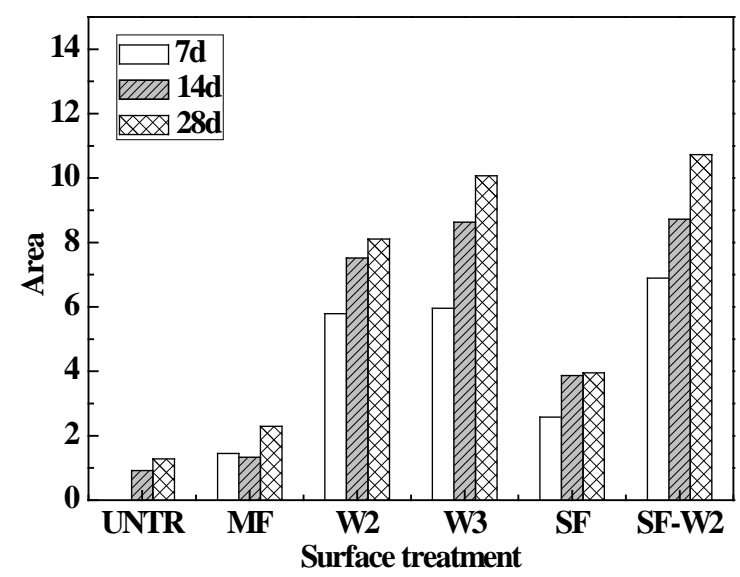

(d) Area of the band at around $1036 \mathrm{~cm}^{-1}$

(silicate-based gel binding of sodium)

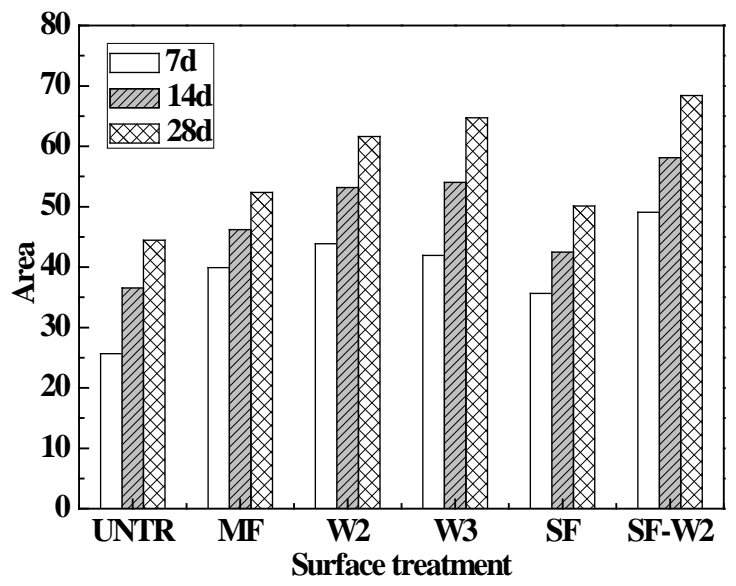

(e) Total area of the band of $\mathrm{Q}_{2}, \mathrm{Q}_{3}, \mathrm{Q}_{4}$, and silicate-based gel binding of sodium

Fig. 5 Variation of the areas of deconvolved components for C-S-H gels. 


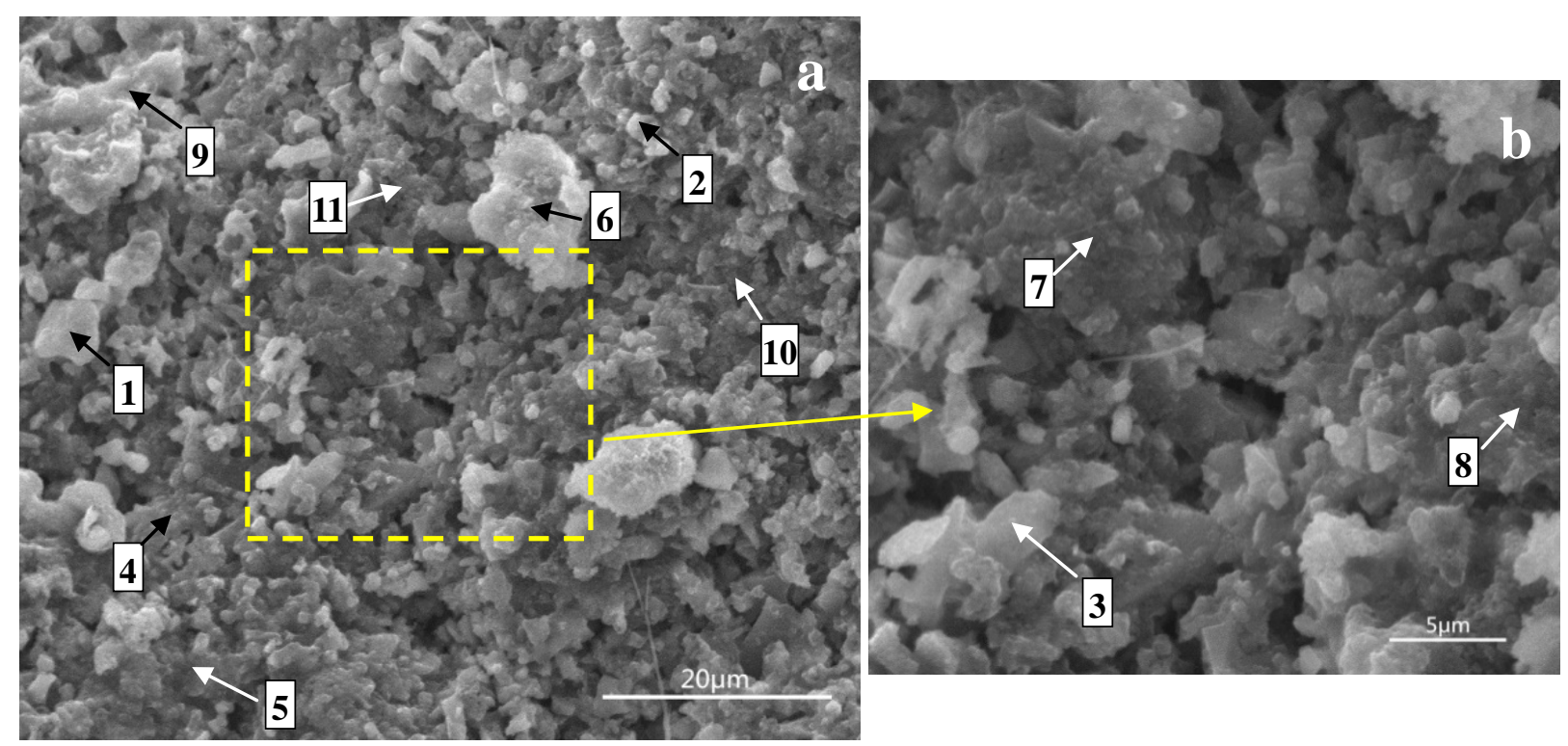

Fig. 6 ESEM images of external surface of UNTR mortar sample at a magnification of 2000 (a) and at a magnification of 5000 (b). 

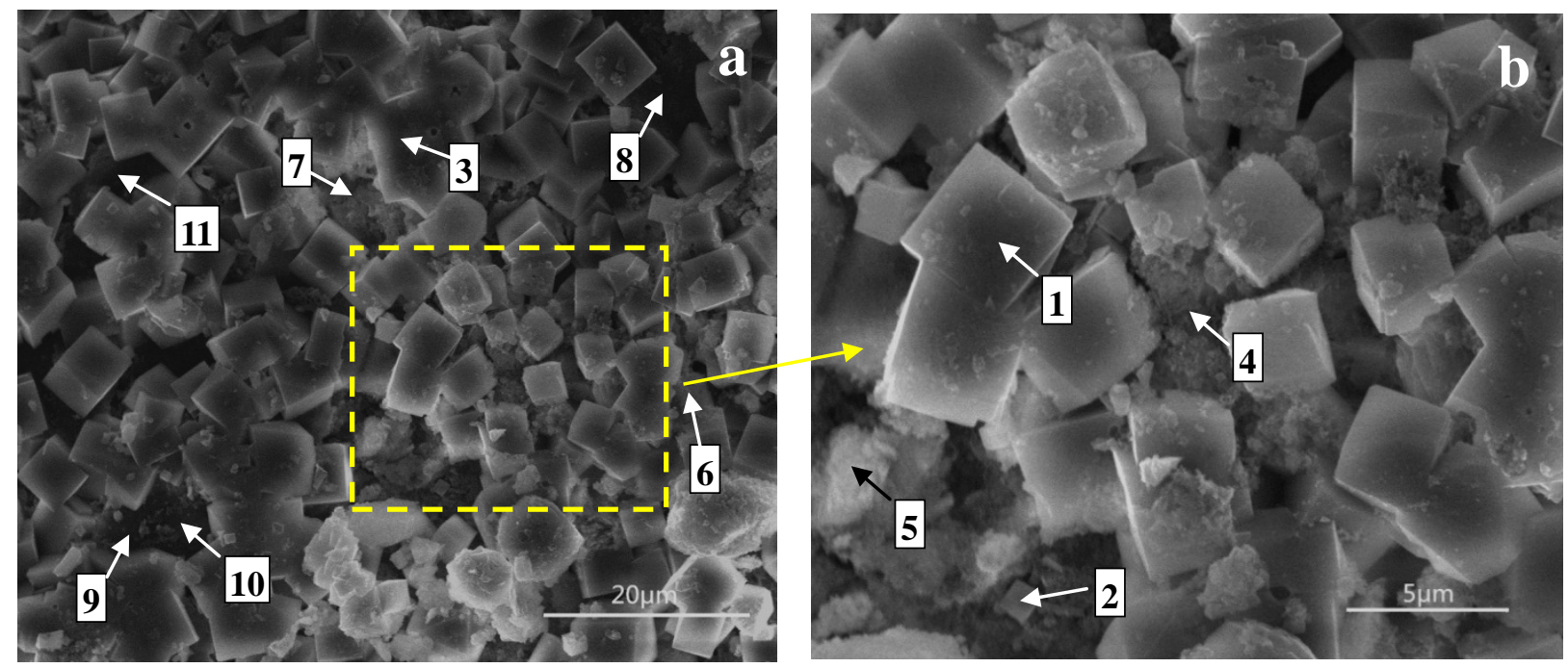

Fig. 7 ESEM images of external surface of MF mortar sample at a magnification of 2000 (a) and at a magnification of 5000 (b). 

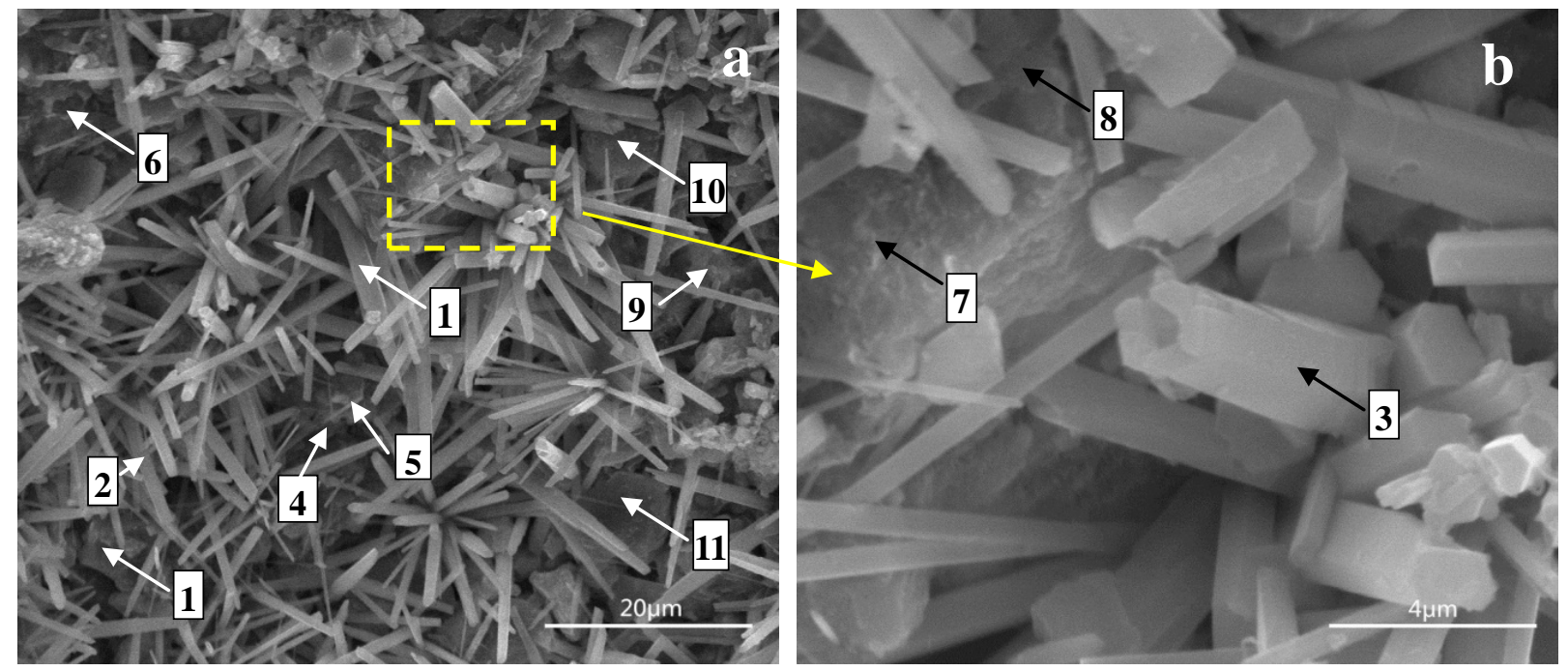

Fig. 8 ESEM images of external surface of W2 mortar sample at a magnification of 2000 (a) and at a magnification of 10000 (b). 

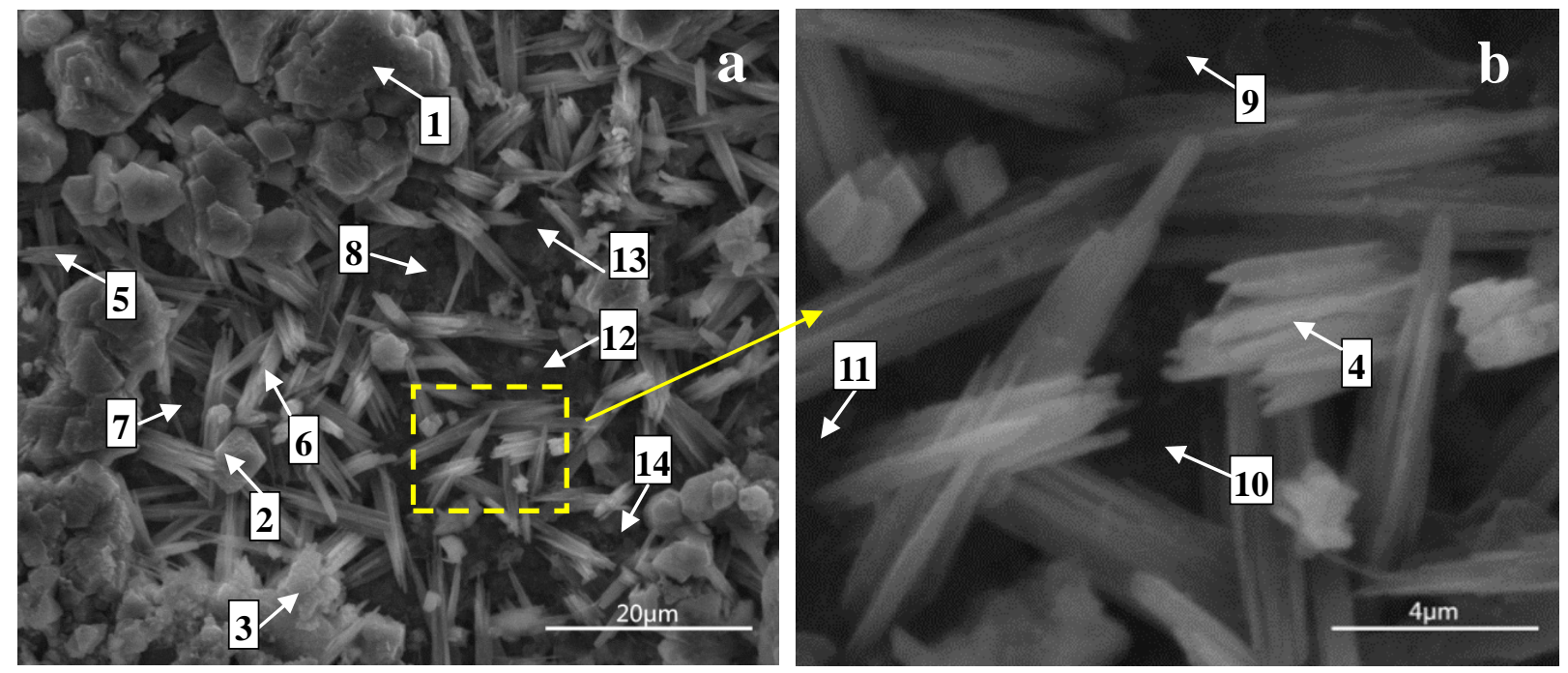

Fig. 9 ESEM images of external surface of W3 mortar sample at a magnification of 2000 (a) and at a magnification of 10000 (b). 

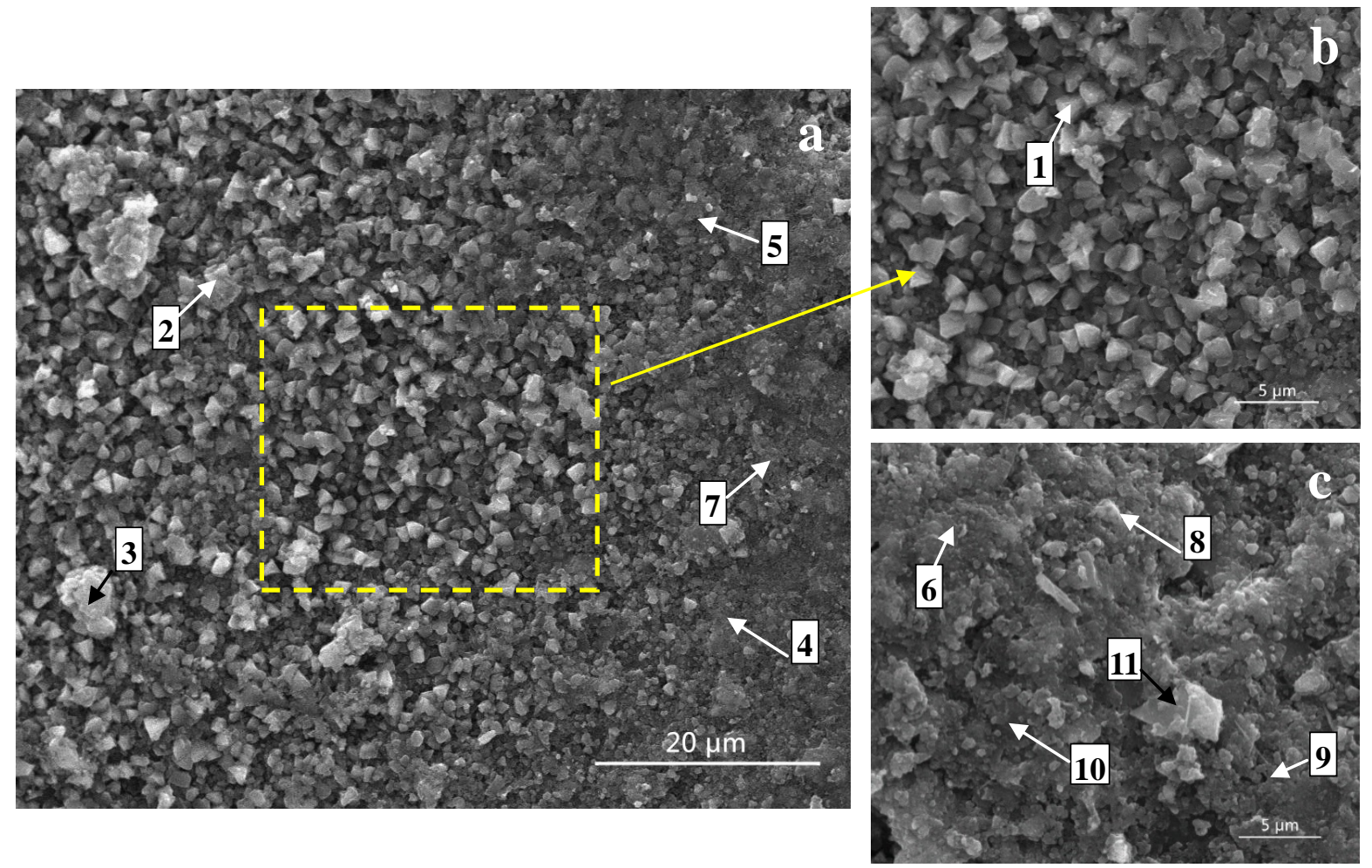

Fig. 10 ESEM images of external surface of SF mortar sample at a magnification of 2000 (a) and at a magnification of 5000 (b and c). 

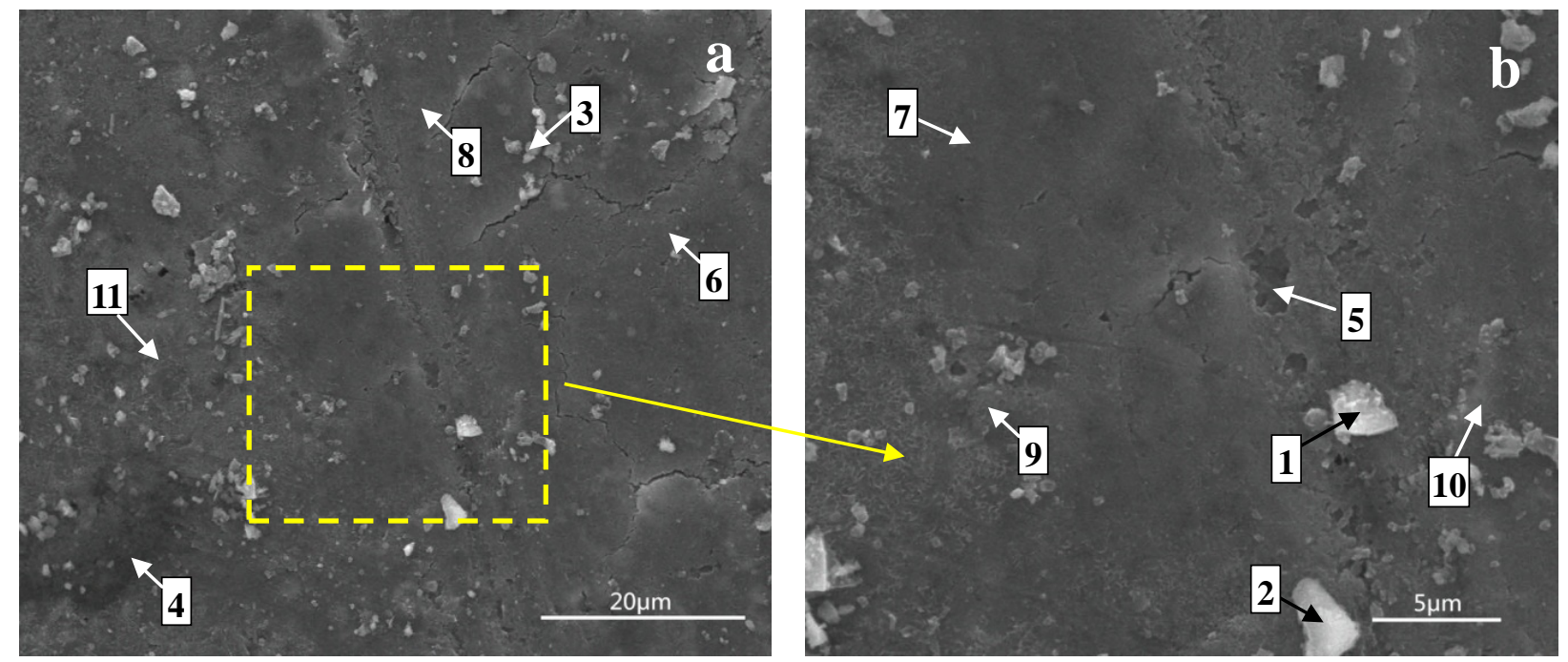

Fig. 11 ESEM images of external surface of SF-W2 mortar sample at a magnification of 2000 (a) and at a magnification of 5000 (b). 